ARTICLE

https://doi.org/10.1038/s41467-019-09367-8

\title{
Successive modification of polydentate complexes gives access to planar carbon- and nitrogen-based ligands
}

Xiaoxi Zhou (1) ${ }^{1}$, Xin Pang ${ }^{2}$, Liming Nie (1) ${ }^{2}$, Congqing Zhu (1) ${ }^{1,4}$, Kaiyue Zhuo ${ }^{1}$, Qingde Zhuo ${ }^{1}$, Zhixin Chen ${ }^{1}$ Gang Liu (i) ${ }^{2}$, Hong Zhang (1) ${ }^{1}$, Zhenyang Lin (1) ${ }^{3}$ \& Haiping Xia (1) ${ }^{1}$

Polydentate complexes containing combinations of nitrogen and carbon ( $\mathrm{N}$ and $\mathrm{C}$ ) ligating atoms are among the most fundamental and ubiquitous molecules in coordination chemistry, yet the formation of such complexes with planar high-coordinate N/C sites remains challenging. Herein, we demonstrate an efficient route to access related complexes with tetradentate CCCN and pentadentate CCCCN and NCCCN cores by successive modification of the coordinating atoms in complexes with a CCCC core. Combined experimental and computational studies reveal that the rich reactivity of metal-carbon bonds and the inherent aromaticity of the metallacyclic skeletons play key roles in these transformations. This strategy addresses the paucity of synthetic approaches to mixed N/C planar pentadentate chelating species and provides valuable insights into the synthesis of carbon-based highcoordinate complexes. Furthermore, the resulting complexes are the examples of organometallic species with combined photoacoustic, photothermal, and sonodynamic properties, which makes them promising for application in related areas.

\footnotetext{
${ }^{1}$ State Key Laboratory of Physical Chemistry of Solid Surfaces and Collaborative Innovation Centre of Chemistry for Energy Materials (iChEM), College of Chemistry and Chemical Engineering, Xiamen University, 361005 Xiamen, China. ${ }^{2}$ State Key Laboratory of Molecular Vaccinology and Molecular Diagnostics, Centre for Molecular Imaging and Translational Medicine, School of Public Health, Xiamen University, 361102 Xiamen, China. ${ }^{3}$ Department of Chemistry, The Hong Kong University of Science and Technology, Clear Water Bay, Kowloon HK, Hong Kong. ${ }^{4}$ Present address: State Key Laboratory of Coordination Chemistry, Jiangsu Key Laboratory of Advanced Organic Materials, School of Chemistry and Chemical Engineering, Nanjing University, 210023 Nanjing, China. Correspondence and requests for materials should be addressed to H.Z. (email: zh@xmu.edu.cn)
} 
C omplexes with polydentate ligands have played a fundamental role in chemistry ${ }^{1,2}$. The most common coordinating atoms in polydentate ligands are donor heteroatoms, such as nitrogen, phosphine, oxygen, and sulfur ${ }^{3,4}$. Notably, carbon can also serve as a coordinating atom in a polydentate complex, and it usually appears in combination with other classical donor atoms ${ }^{5,6}$; such complexes have been theoretically and experimentally examined due to their unique structural, electronic, aromatic, catalytic, and optical properties $^{7-10}$. Among these polydentate complexes, planar systems involving both nitrogen and carbon donors have flourished and have attracted great attention in recent decades ${ }^{11,12}$. As shown in Fig. 1a, complexes with combinations of $\mathrm{N}$ and $\mathrm{C}$ coordination sites, such as bidentate $\mathrm{NC}$ cores ${ }^{13,14}$, tridentate $\mathrm{NCN}$ cores ${ }^{15,16}$, and $\mathrm{CNC} / \mathrm{CCN}$ cores $^{17,18}$, exhibit multiple functions and have had a substantial impact on emerging areas in chemistry. For complexes with higher planar coordination configurations, examples are limited, and the majority of coordinating sites are occupied by nitrogens. Representative examples include the tetradentate complexes known as carbaporphyrinoid systems, in which one or two pyrrolic units of the porphyrin motif are replaced by inverted pyrrolic rings or carbocyclic units (Fig. 1a $)^{19-22}$. To date, the chemistry of molecules with higher planar carbon/nitrogen $(\mathrm{C} / \mathrm{N})$ coordination sites, such as those allowing penta- and hexacoordination, remains unexplored owing to the inaccessibility of the atypical geometries, especially for the complexes based on transition metal centers.

As a distinctive family of complexes, metallaaromatics have attracted considerable attentions in recent years ${ }^{23-29}$, and their inherent aromaticity facilitates the bonding of carbon chains with a variety of transition metals. The conjugated carbon chains in these complexes have been viewed as carbon-based polydentate ligands, although these ligands differ from classic ligands in coordination and dissociation. Metallaaromatics with bidentate NC cores (metallapyridines) ${ }^{14}$ or tridentate CCN cores (metallabenzothiazoliums) ${ }^{18}$ have been demonstrated (Fig. 1a). Inspired by the rich reactivities of metal-carbon bonds, we attempted to directly modify metallaaromatic complexes with planar carbon ligands in the hope of generating planar polydentate ligand systems with high N/C combined coordination.

Herein, we report the successive transformation of the coordinating atoms in complex with a CCCC core, which can undergo unique changes in molecular topology, such as a shift of the aromatic unit. Efficient modifications can lead to the discovery of a series of carbon-based high-coordinate N/C ligand systems and the unique planar N/C pentadentate complexes (Fig. 1b), which involve metal centers located at the center of planar four-, five-, or six-membered metallacycles. Interestingly, the resulting complexes exhibit good photoacoustic (PA), photothermal, and sonodynamic properties, making them potentially applicable as theranostic agents.

\section{Results}

From CCCC to CCCCN complexes. For common, highcoordination polydentate complexes, the ordered equatorial arrangement of the coordinating atoms provides a unique environment for metal binding, hindering the direct replacement of coordinating atoms. However, the strained metallacyclopropene unit in CCCC complex $\mathbf{1}$ exhibits a strong tendency to undergo ring expansion ${ }^{30-32}$. We thus attempted reactions of 1 with various nitrogen-containing reagents. As shown in Fig. 2, the reaction of complex 1 with 2-ethynylpyridine in the presence of $\mathrm{AgClO}_{4}$ generates CCCCN complex 2 in $92 \%$ yield. We inferred that $\mathrm{AgClO}_{4}$ might serve as a dechlorinating/oxidizing agent to facilitate the $[3+2]$ cycloaddition and deprotonation steps. An ${ }^{18} \mathrm{O}$-labeling experiment indicates that the oxygen atom on $\mathrm{C} 8$ comes from the trace amount of $\mathrm{H}_{2} \mathrm{O}$ existing in solution. A possible mechanism for the formation of $\mathbf{2}$ is presented in Supplementary Figure 1.

Complex 2 was characterized by spectroscopic and analytical techniques, and its solid-state structure was determined by single-

a Representative examples with planar N/C joint coordination sites

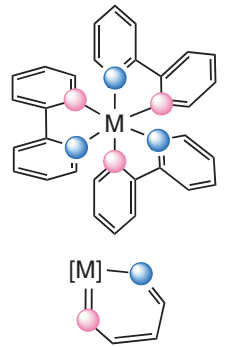

Bidentate complexes
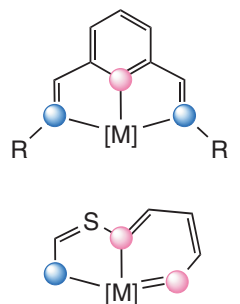

Tridentate complexes Tetradentate complex

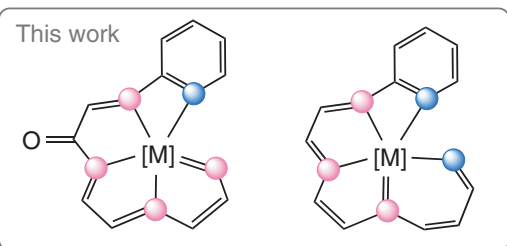

Pentadentate complexes

b Successive modification of coordination atoms in planar high coordination complexes (this work)

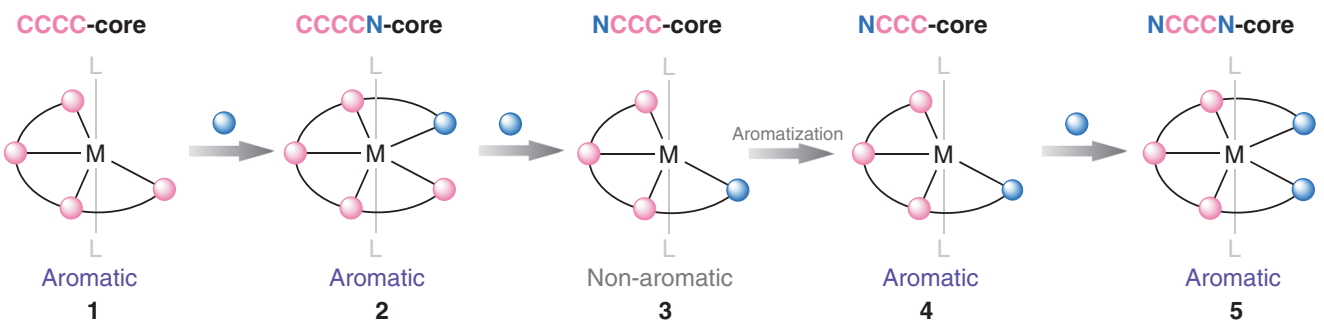

Fig. 1 Background and schematic outline of the strategy. a Representative examples of polydentate complexes with planar nitrogen/carbon (N/C) joint coordination sites. $\mathbf{b}$ Successive and direct transformation of coordinating atoms in complexes with a CCCC core via reactions of the metal-carbon bonds to generate planar N/C high-coordinate complexes (this work) 


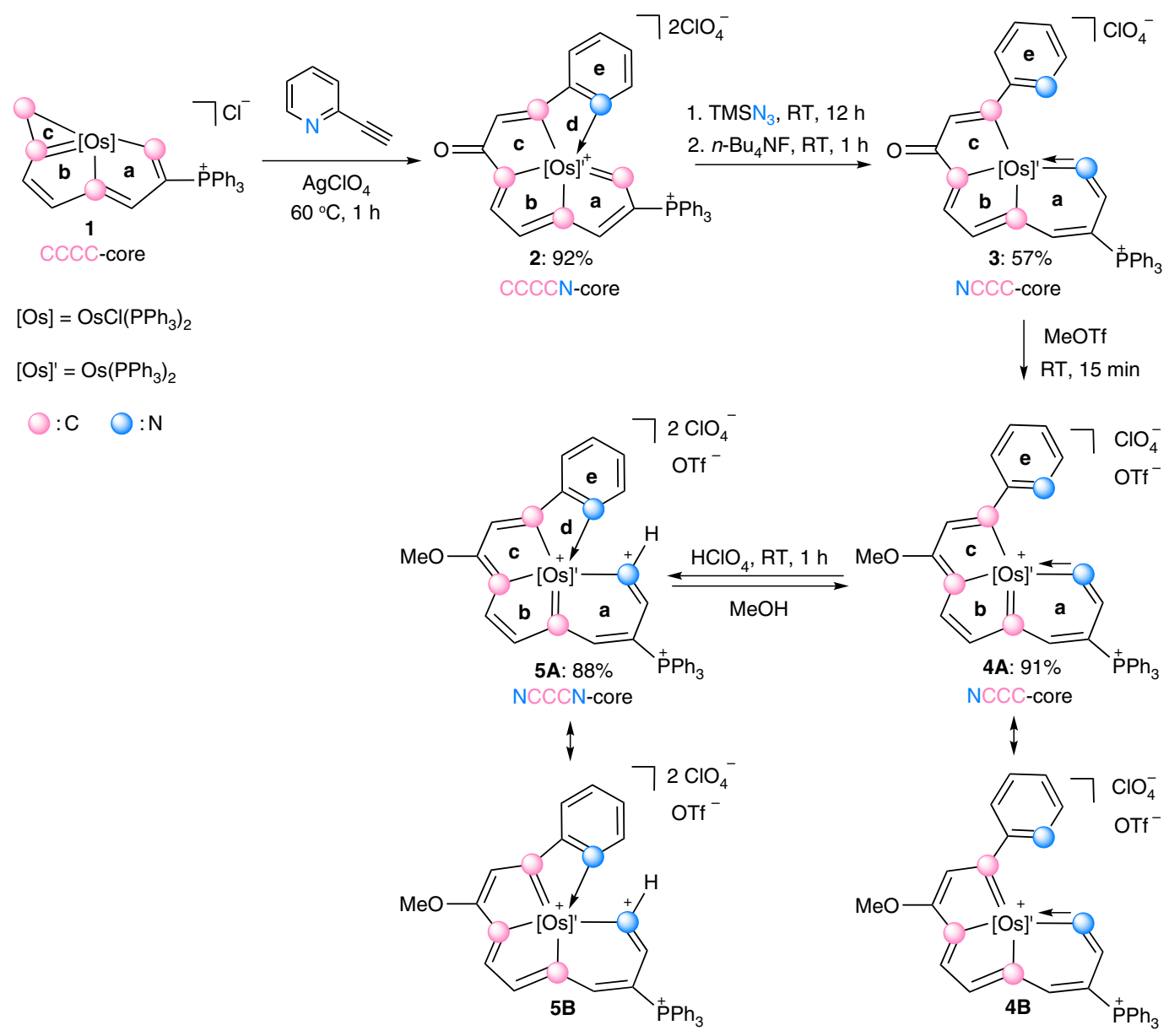

Fig. 2 Successive transformations of polydentate complexes. Transformations of CCCC (1) to CCCCN (2), NCCC (3, 4), and NCCCN (5) type complexes

crystal X-ray diffraction (Fig. 3a and Supplementary Figure 2). Interestingly, the CCCC Os coordination in 1 was converted to CCCCN Os coordination in $\mathbf{2}$. The metal center in $\mathbf{2}$ features a pentagonal bipyramidal geometry, and the five coordination positions in the equatorial plane are occupied by four carbon atoms and one nitrogen atom. The equatorial polycyclic ring system (rings $\mathbf{a}, \mathbf{b}, \mathbf{c}, \mathbf{d}$, and $\mathbf{e}$ ) consists of 17 atoms (Os1, N1, and $\mathrm{C} 1-\mathrm{C} 15)$, which are nearly coplanar, as reflected by the small mean deviation from the least-squares plane $(0.049 \AA)$. The bond distances of rings $\mathbf{a}$ and $\mathbf{b}$ are within the range of typical electrondelocalized systems and similar to those observed in osmapentalenes ${ }^{33}$, whereas the bonds in rings $\mathbf{c}$ and $\mathbf{d}$ display obvious deviations from their ideal distances. The Os1-N1 bond length is 2.232(4) $\AA$, which is comparable to lengths typically reported for coordinated pyridine units (bond lengths and angle ranges in this article are all based on a search of the Cambridge Structural Database, CSD version 5.39 in November 2017), indicating its dative bond character. Complex 2 exhibited a nuclear magnetic resonance (NMR) spectrum consistent with the putative fused metallapentalene, and the ${ }^{1} \mathrm{H}$ chemical shifts of rings $\mathbf{a}$ and $\mathbf{b}(\delta$ $14.2\left(\mathrm{C}^{1} H\right), 9.1\left(\mathrm{C}^{3} H\right), 9.7\left(\mathrm{C}^{5} H\right)$, and $8.1\left(\mathrm{C}^{6} H\right)$ parts per million $(\mathrm{ppm}))$ are similar to those reported for metallapentalene species $^{33}$.

From CCCCN to NCCC complexes. The bond length of Os1-C1 in 2 is 2.046(5) $\AA$, and the chemical shifts of this unit are $14.2 \mathrm{ppm}$ for $\mathrm{C} 1 \mathrm{H}$ and $232.4 \mathrm{ppm}$ for $\mathrm{C} 1$, indicating its carbene character. Therefore, we investigated reactions of $\mathbf{2}$ with nucleophiles. Indeed, treating $\mathbf{2}$ with azidotrimethylsilane $\left(\mathrm{TMSN}_{3}\right)$ and tetrabutylammonium fluoride $\left(n-\mathrm{Bu}_{4} \mathrm{NF}\right)$ led to the formation of complex 3 with a tetradentate ligand (Fig. 2).

The solid-state structure of 3 was probed by single-crystal Xray diffraction (Fig. $3 \mathrm{~b}$ and Supplementary Figure 3), which confirmed the formation of a ring expansion product from the parent five-membered ring. The tricyclic topology involves a sixmembered aza-metallacycle fused to two five-membered metallacycles, and the equatorial coordination sites around the osmium center are filled by the NCCC-type tetradentate ligand. Notably, the inserted nitrogen atom is incorporated in cumulated double bonds, as indicated by the Os1-N1 bond length of $1.891(3) \AA$ and the $\mathrm{N} 1-\mathrm{C} 1$ bond length of $1.270(5) \AA$. The Os1-N1-C1 bond angle of the cumulated double bonds deviates considerably from linearity $\left(144.6(3)^{\circ}\right)$, and the angle is smaller than all previously reported bond angles of azavinylidene complexes $\left(150.9^{\circ}-179.6^{\circ}\right)$. Complex 3 contains a considerable alternation in the carbon-carbon bond lengths in rings $\mathbf{a}$ and $\mathbf{b}$, indicating a change in the aromaticity of the metallacycles compared to those in complex 2. As with the results of X-ray diffraction, the ${ }^{1} \mathrm{H}$ NMR signals of rings $\mathbf{a}$ and $\mathbf{b}$ in $\mathbf{3}$ are distinct from those observed in 2; the protons of the metallacycles exhibited obvious up-field shifts to $\delta 4.5\left(\mathrm{C}^{1} H\right), 5.9\left(\mathrm{C}^{3} \mathrm{H}\right), 5.4\left(\mathrm{C}^{5} \mathrm{H}\right)$, and $7.5\left(\mathrm{C}^{6} \mathrm{H}\right)$ ppm. The up-field shifts of the resonances are likely due to the dearomatization of the metallapentalene unit via the nitrogen insertion reaction.

Of particular note in the transformation of seven-coordinate 2 to six-coordinate 3 is the change in the $\mathrm{C} / \mathrm{N}$ incorporated polydentate ligands. The observation that treatment of a complex 
a
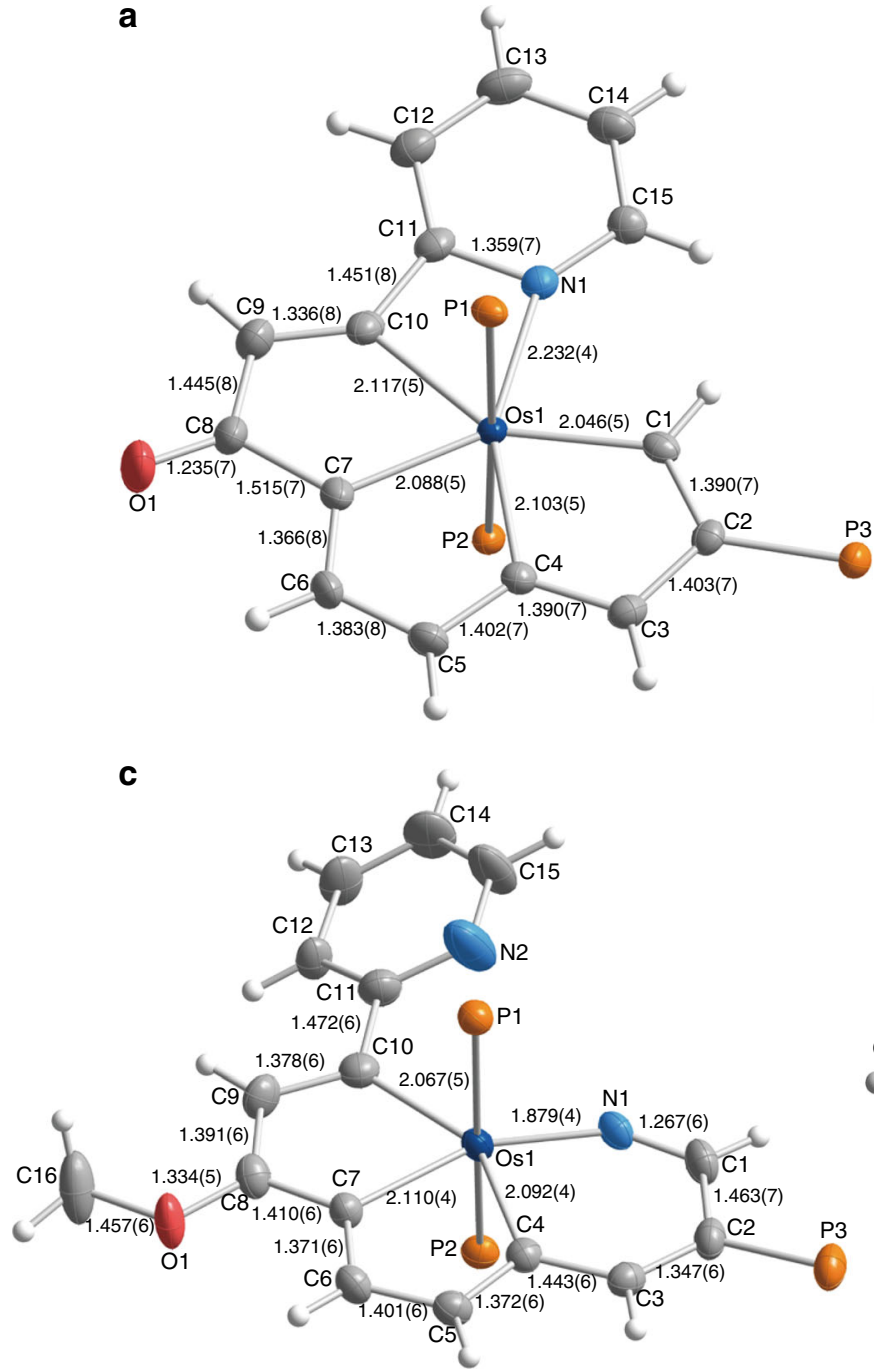

b

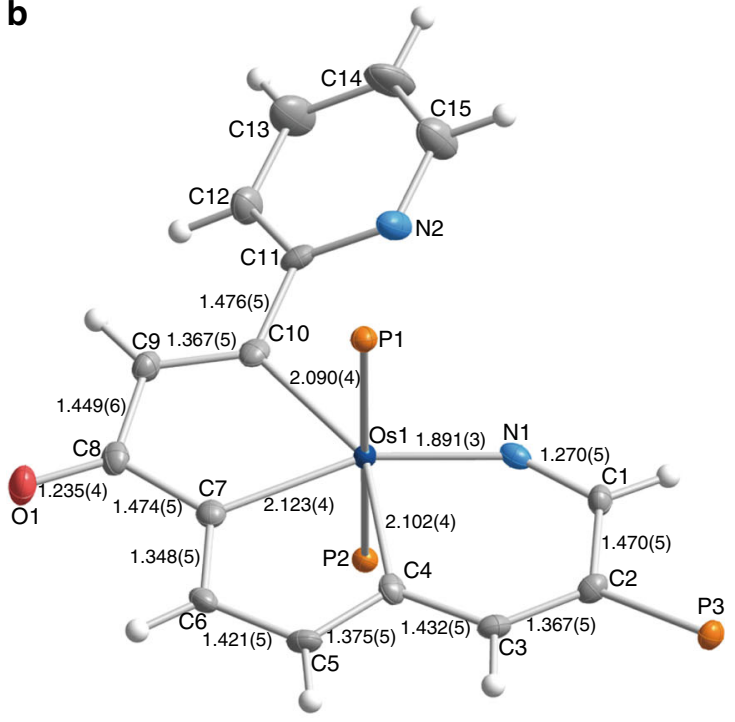

d

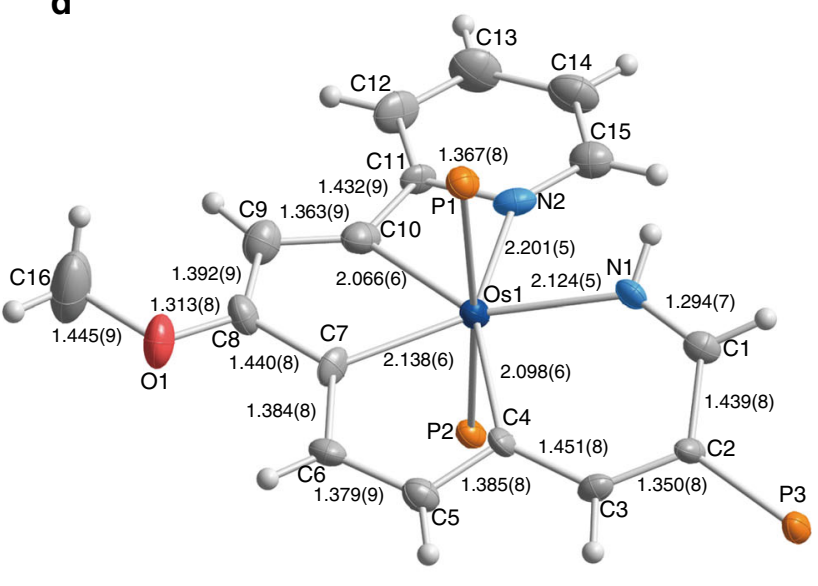

Fig. 3 X-ray structures of the cationic parts of $\mathbf{2}(\mathbf{a}), \mathbf{3}(\mathbf{b}), \mathbf{4}(\mathbf{c})$, and $\mathbf{5}$ (d). Thermal ellipsoids are set at the $50 \%$ probability level. The phenyl groups in the $\mathrm{PPh}_{3}$ moieties are omitted for clarity

containing a pentadentate CCCCN core with an azide yields a product having the NCCC core was a great surprise owing to the known stability and inertness of pentadentate chelates, and in the literature, they mainly undergo typical ligand substitution or dissociation reactions ${ }^{32,34}$. Figure 4 shows the calculated energy profile based on the proposed mechanism for the experimentally observed transformation of 2 to 3 . The ligand substitution of $\mathrm{PPh}_{3}$ with azidotrimethylsilane is followed by the release of $\mathrm{N}_{2}$, which initiates the reaction to generate the intermediate $\mathbf{B}$. The nitrogen insertion step, which involves a structural rearrangement to give the six-membered intermediate $\mathbf{C}$, is kinetically favorable with a small barrier of $7.9 \mathrm{kcal} \mathrm{mol}^{-1}$. In addition, the intermediate $\mathbf{C}$ is significantly more stable than the intermediate $\mathbf{B}$, as a result of the $\mathrm{C}-\mathrm{N}$ bond formation. Finally, elimination of the trimethylsilyl group in the presence $n$ - $\mathrm{Bu}_{4} \mathrm{NF}$ and recoordination of a $\mathrm{PPh}_{3}$ ligand produce the final product 3 .

The methylation of the NCCC complex. To aromatize 3, we chose methyl trifluoromethanesulfonate (MeOTf) as the electrophile. As shown in Fig. 2, reaction of 3 with MeOTf afforded complex 4, in which the original carbonyl group was methylated, in high yield. The ${ }^{1} \mathrm{H}$ NMR spectrum of 4 clearly shows the protons of the metallacycles at $\delta 5.6\left(\mathrm{C}^{1} \mathrm{H}\right), 7.0\left(\mathrm{C}^{3} \mathrm{H}\right), 7.0\left(\mathrm{C}^{5} \mathrm{H}\right)$,
$8.8\left(\mathrm{C}^{6} \mathrm{H}\right)$, and $8.3\left(\mathrm{C}^{9} \mathrm{H}\right) \mathrm{ppm}$, which are considerably lower field than those of complex $3\left(4.5\left(\mathrm{C}^{1} \mathrm{H}\right), 5.9\left(\mathrm{C}^{3} \mathrm{H}\right), 5.4\left(\mathrm{C}^{5} \mathrm{H}\right), 7.5\right.$ $\left(\mathrm{C}^{6} \mathrm{H}\right)$, and $\left.7.4\left(\mathrm{C}^{9} \mathrm{H}\right) \mathrm{ppm}\right)$, suggesting that the tricyclic framework was aromatized. The aromatic structure indicated by the NMR spectra was further confirmed by a single-crystal X-ray diffraction study of 4 (Fig. $3 c$ and Supplementary Figure 4). Visually, the structure appears similar to complex 3, as the metal center is also six-coordinate and bound to an NCCC-type tetradentate ligand. The most prominent difference is that complex 4 has a fused metallapentalenoid configuration in which all the bond distances in the metallacycles clearly fall in the aromatic range. The mean deviation from the least-squares plane through Os1, N1, and C1-C10 is $0.032 \AA$, indicating good planarity of the tricyclic ring system. The bond lengths of the $\mathrm{Os}-\mathrm{C}$ and $\mathrm{C}-\mathrm{C}$ bonds within the two five-membered metallacycles are comparable to those reported for metallapentalenes (1.926-2.139 $\AA$ for the Os-C bond lengths and 1.367-1.410 $\AA$ for the $\mathrm{C}-\mathrm{C}$ bond lengths $)^{33}$, which is consistent with the assignment of a metallapentalene unit. Together with the fused six-membered azametallacycle (ring a), the core of complex 4 can be described as a metal-containing pentalene system fused to a pyridine. The structural parameters suggest contributions from both resonance forms, $\mathbf{4 A}$ and $\mathbf{4 B}$ shown in Fig. 2. Remarkably, complex 4 represents a unique aromatic scaffold in which the metal center is 


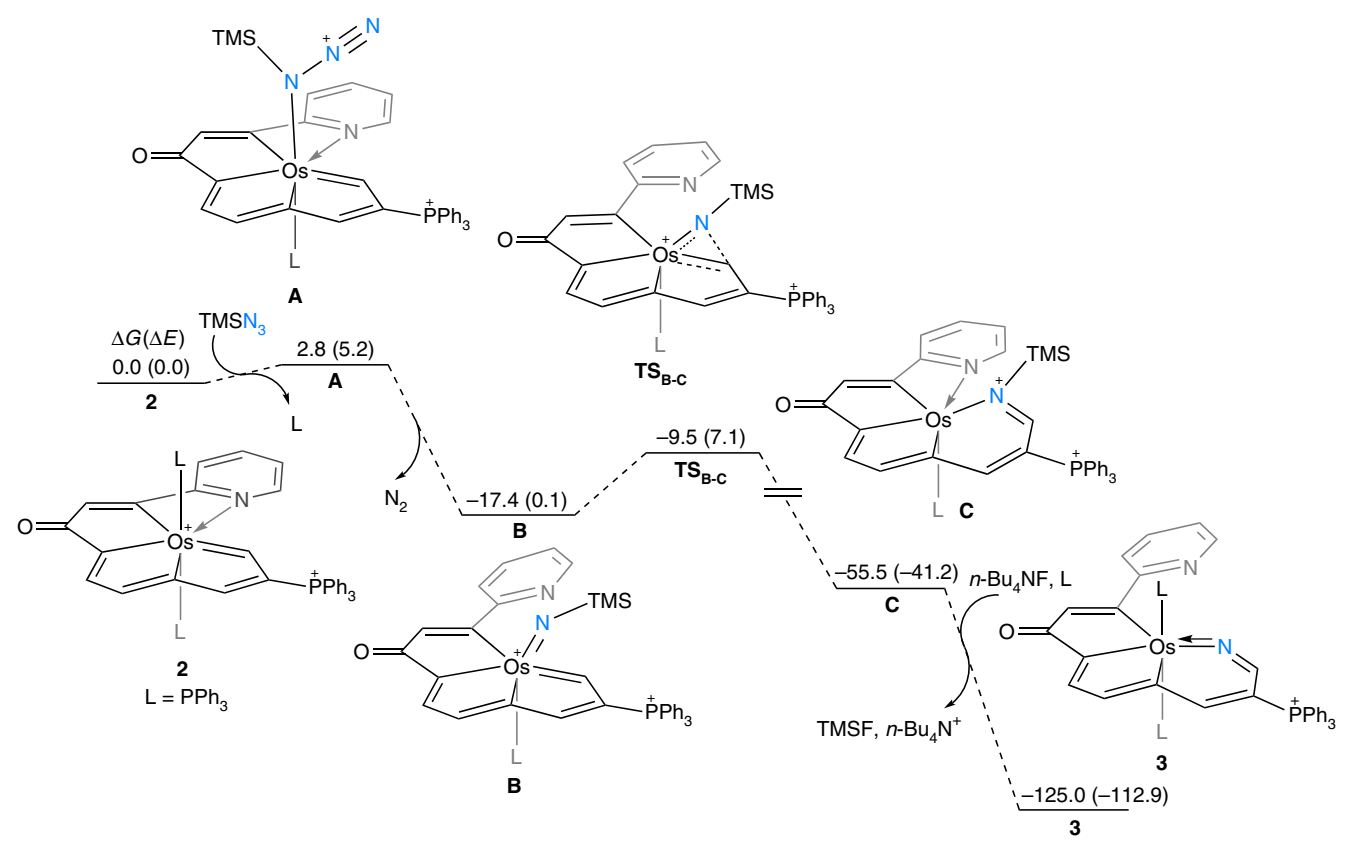

Fig. 4 Calculated energy profile for the formation of structure 3. The relative Gibbs free energies and electronic energies (within parentheses) are given in $\mathrm{kcal} \mathrm{mol}^{-1}$

shared by two five-membered rings and a six-membered ring. Considerable progress has been made in the synthesis of metallaaromatics with various scaffolds ${ }^{23-29}$. However, synthetic route to metallapyridines is very limited $14,35,36$. Complex 4 represents a rare example of fused-ring metallapyridine framework. In 2012, we reported a sulfur-tethered metallapyridine complex through an annulation reaction of a metallabenzene derivative ${ }^{35}$. The metallapyridine unit of the complex can be viewed as $m$-metallapyridine, in which the nitrogen atom is not adjacent to the metal center. By comparison, the o-metallapyridine unit in complex 4 is similar to the previous monocyclic examples tantalapyridine ${ }^{36}$ and osmapyridine ${ }^{14}$.

Conversion of NCCC complexes to NCCCN complexes. The addition of excess acid to NCCC-type complex 4 in solution resulted in the re-coordination of the pyridine unit to the metal center. As shown in Fig. 2, the protonation of the nitrogen atom in the osmapyridine unit (ring a) of $\mathbf{4}$ in the presence of perchloric acid afforded NCCCN-type complex $\mathbf{5}$ in $88 \%$ isolated yield. These results demonstrate that the nitrogen atom of the osmapyridine unit (ring a) in $\mathbf{4}$ is more reactive towards electrophiles than that of the pyridine (ring e), which can be rationalized by discrete fourier transform (DFT) calculations (Supplementary Figure 6). The calculated highest occupied molecular orbital (HOMO) of $\mathbf{4}$ is mainly located on the metallacycles. Interestingly, the protonation of $\mathbf{4}$ is reversible. Treatment of $\mathbf{5}$ with a protic solvent, such as methanol, leads to the elimination of the proton and quantitatively regenerates 4 .

The identification of $\mathbf{5}$ was supported by solution and solidstate characterization techniques. The solid-state structure confirmed the presence of a seven-coordinate osmium center, in which two of the coordination sites are similar to those in 2 (two axial phosphine ligands), and the other five coordination sites in the equatorial plane are occupied by three carbon atoms and two nitrogen atoms (Fig. $2 \mathrm{~d}$ and Supplementary Figure 5). The bond distances within the two five-membered metallacycles and the six-membered metallacycle vary slightly from those in parent compound 4, whereas the Os1-N1 bond length is markedly elongated to 2.124 (5) $\AA$ due to the protonation of the nitrogen atom. The structural parameters indicate $\mathbf{5}$ can be represented by the resonance structures $\mathbf{5 A}$ and $\mathbf{5 B}$, as a metallapentalene fused metallapyridinium. A closely related monocyclic osmapyridinium has been reported through the formal $[4+2]$ cycloaddition reaction of 1-metalla-1,3-dienes with nitriles ${ }^{14}$. The bond lengths of Os1-C4 (2.098(6) $\AA$ ) and Os1-N1 $(2.124(5) \AA)$ in 5 are longer than those of the monocyclic osmapyridinium (Os-C 1.943(9) $\AA$ and Os $-\mathrm{N}$ $1.952(7) \AA)^{14}$, probably due to the lessened electron delocalization in the fused osmapyridinium ring and the structural distortion induced by steric hindrance (vide infra), respectively. The $\mathrm{C} 1-\mathrm{N} 1$ bond length (1.294(7) $\AA$ ) is almost identical with that of the monocyclic osmapyridinium $(1.294(12) \AA)^{14}$, but is longer than that of 4 (1.267(6) $\AA$ ). Compared to the monocyclic osmapyridine $^{14}$, the osmapyridine units in both complexes 4 and 5 show slight bond distance alternation, which may be caused by the weakened electron delocalization in the fused-ring systems. The bicyclic metallapentalene rings (rings $\mathbf{b}$ and $\mathbf{c}$ ) and the metallapyridium ring (ring a) deviate slightly from planarity, as reflected by their mean deviations from the least-squares plane (0.084 and $0.113 \AA$, respectively). The overall pentacyclic core of 5 (Os1, N1, N2, C1-C15) displays a noticeable distortion with a mean deviation from the least-squares plane of $0.254 \AA$, which is probably due to the steric hindrance between the two hydrogen atoms $(\mathrm{N} 1 \mathrm{H}$ and $\mathrm{C} 15 \mathrm{H})$. The involvement of $\mathrm{N} 1 \mathrm{H}$ in resonance was confirmed by the broad peak at $11.3 \mathrm{ppm}$ in its ${ }^{1} \mathrm{H}$ NMR spectrum. The remaining protons on the metallacycle were observed at shifts typical of metallaaromatic protons $\left(9.3\left(\mathrm{C}^{1} \mathrm{H}\right)\right.$, $7.6\left(\mathrm{C}^{3} \mathrm{H}\right), 8.3\left(\mathrm{C}^{5} \mathrm{H}\right), 8.4\left(\mathrm{C}^{6} \mathrm{H}\right)$, and $\left.8.8\left(\mathrm{C}^{9} \mathrm{H}\right) \mathrm{ppm}\right)$ and are entirely consistent with the delocalized bonding in the three fused metallacycles.

DFT computational study. To elucidate the bonding and electronic structures of these unique polydentate complexes, we carried out DFT calculations on the simplified unsubstituted models $2^{\prime}-5^{\prime}$ by replacing $\mathrm{PPh}_{3}$ with $\mathrm{PH}_{3}$. The optimized structural parameters of $\mathbf{2}^{\prime}-\mathbf{5}^{\prime}$ agree well with those observed in the crystal structures of $\mathbf{2 - 5}$, respectively. The trend in the calculated Wiberg bond indices for the Os-C and Os-N bonds of the model 
a $\operatorname{NICS}(1)_{z z}(\mathrm{ppm})$

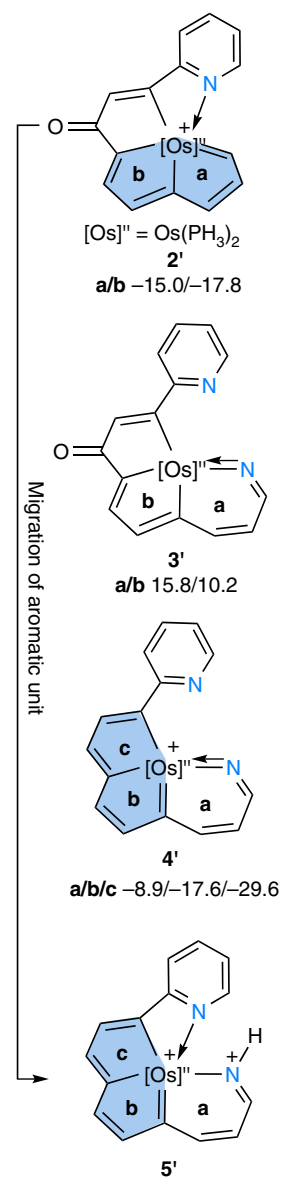

b

ACID analysis
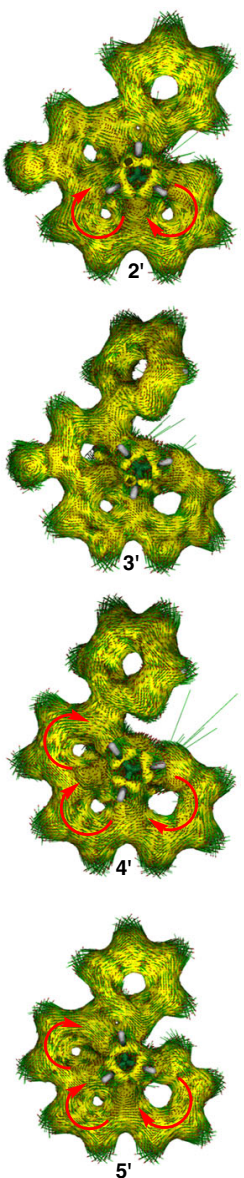

C ASE $\left(\mathrm{kcal} \mathrm{mol}{ }^{-1}\right)$
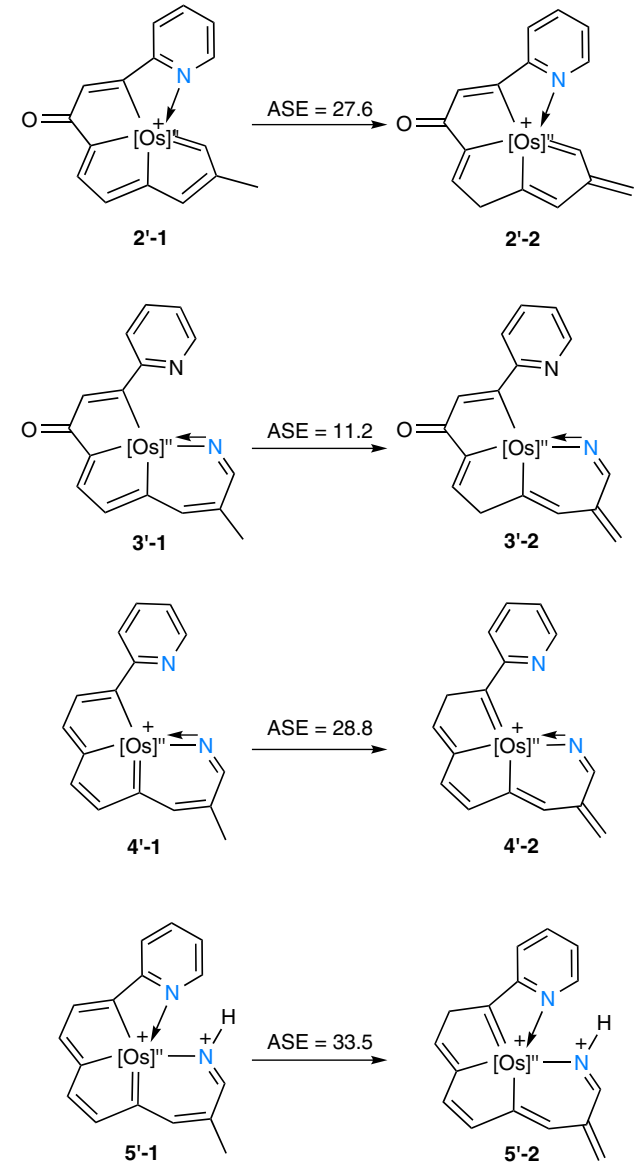

Fig. 5 Aromaticity evaluations. a NICS(1) $z z$ (nucleus-independent chemical shift along the $z$-axis at $1 \AA$ above the ring critical point, ppm) evaluations of the aromaticity of model complexes $\mathbf{2}^{\prime}-\mathbf{5}^{\prime}$. Blue rings: The migration of the osmapentalene unit from rings (a, b) to rings (b, c). b Anisotropy of the currentinduced density (ACID) plot of model complexes $\mathbf{2}^{\prime}-\mathbf{5}^{\prime}$ with an isosurface value of 0.025 . The magnetic field vector is orthogonal to the ring plane and points upward. c Aromatic stabilization energy (ASE, $\mathrm{kcal} \mathrm{mol}^{-1}$ ) evaluations of model complexes $\mathbf{2}^{\prime}-\mathbf{5}^{\prime}$

complexes $\mathbf{2}^{\prime}-\mathbf{5}^{\prime}$ is consistent with that in the relevant bond lengths of the X-ray molecular structures (Supplementary Figure 7). Taking the NCCCN-type complex $5^{\prime}$ as an example, the Wiberg bond indices are 0.88, 0.76, and 0.89 for Os1-C4, Os1-C7, and Os1-C10, respectively (Supplementary Figure 7d), suggesting strongly covalent $\mathrm{Os}-\mathrm{C}$ bonding between the osmium center and the carbons. The Wiberg bond index of Os1-N1 (0.64) is slightly larger than Os1-N2 (0.51), which could be attributed to the $\pi$-electron delocalization within the metallapyridinium ring. The main characteristic of the orbital interactions in the aromatic metallacycles of $2^{\prime}, 4^{\prime}$, and $5^{\prime}$ is the involvement of two filled metal $d$ orbitals $\left(d_{x z}\right.$ and $\left.d_{y z}\right)$ in the $\pi$ bonding. The key occupied $\pi$ molecular orbitals ( $\pi$-MOs) of complexes $2^{\prime}, 4^{\prime}$, and $5^{\prime}$, which reflect the $\pi$-delocalization along the perimeter of the polycyclic system, are shown in Supplementary Figure 8-10. The MOs are derived principally from the orbital interactions between the $p_{\pi}$ orbitals of the organic fragment and the $d$ orbitals of the Os atom $\left(5 d_{x z}\right.$ and $\left.5 d_{y z}\right)$. For example, the HOMO and HOMO-13 $(\pi$ symmetry) in $\mathbf{2}^{\prime}$ mainly reflect interactions between the metal $d_{\mathrm{xz}}$ orbital and the $p_{\pi}$ orbitals of organic fragment orbital, and HOMO-4 and HOMO-9 ( $\delta$ symmetry) of $2^{\prime}$ show interactions between the metal $d_{\mathrm{yz}}$ orbital and the $p_{\pi}$ orbitals of organic fragment orbital (Supplementary Figure 8).

The equalized bond lengths and good stability of the complexes (2, 4, and 5) and the experimentally observed dearomatization-aromatization process (from 2 to 3 and from 3 to 4) prompt us to examine the aromaticity of these polycyclic species. DFT computational studies were then carried out to elucidate the aromaticity of the tetra- and pentadentate complexes. We calculated the nucleus-independent chemical shift (NICS) values ${ }^{37-39}$ along the $z$-axis at $1 \AA$ above the ring critical point $\left(\operatorname{NICS}(1)_{z z}\right)$ of model complexes $\left(2^{\prime}, 3^{\prime}, 4^{\prime}\right.$, and $\left.5^{\prime}\right)$. The average value was used when the environments above and below the ring centers were not equivalent. In general, negative NICS values indicate aromaticity. As depicted in Fig. 5a, all the calculated NICS values for complex 2 (rings a and b), complex 4 (rings $\mathbf{a}, \mathbf{b}$, and $\mathbf{c}$ ), and complex $\mathbf{5}$ (rings $\mathbf{a}, \mathbf{b}$, and $\mathbf{c}$ ) are negative, which is in sharp contrast with those of model complex $\mathbf{3}^{\prime}$ (rings a and $\mathbf{b}$ ). The aromaticity of the model complexes is further supported by the anisotropy of the current-induced density (ACID) $)^{40,41}$ calculations. As shown in Fig. 5b and Supplementary Figure 11-14, the obvious diatropic ring currents (clockwise vectors) demonstrate the aromaticity of the fused five-membered rings of $\mathbf{2}^{\prime}$ and the two fused five-membered rings and sixmembered rings of $\mathbf{4}^{\prime}$ and $\mathbf{5}^{\prime}$, whereas no clear diatropic or paratropic ring currents could be found in the five-membered ring or the six-membered ring of $3^{\prime}$.

We also evaluated the aromatic stabilization energy (ASE) by employing the isomerisation method introduced by Schleyer and Pühlhofer ${ }^{42,43}$. As shown in Fig. 5c, ASE values of 27.6, 28.8, and 
$33.5 \mathrm{kcal} \mathrm{mol}^{-1}$ were calculated for complexes $\mathbf{2}^{\prime}, \mathbf{4}^{\prime}$, and $\mathbf{5}^{\prime}$, respectively; these values are comparable to those of other reported fused metallaaromatics ${ }^{44}$, but are much larger than the calculated ASE value $\left(11.2 \mathrm{kcal} \mathrm{mol}^{-1}\right)$ of $3^{\prime}$. Different isomeric model complexes have been tested for the ASE calculations (Supplementary Figure 15), which present similar values. In combination with experimental data, the NICS values and the ACID evaluation, complex $\mathbf{3}$ is considered as non-aromatic, although the model complex $\mathbf{3}^{\prime}-\mathbf{1}$ gives positive ASE value. A positive ASE value of non-aromatic $\mathbf{3}^{\prime}-\mathbf{1}$ may be ascribed to the partial conjugated fragment within the two fused rings ( $\mathbf{a}$ and $\mathbf{b}$ ), which could increase the stability with comparison to the nonconjugated isomer $\mathbf{3}^{\prime} \mathbf{- 2}$.

These calculation results nicely confirm the aromatic nature of the chelates, which should account for the successive transformation process from the complex containing the CCCCN-type ligand (2) to a species containing an NCCCN-type ligand (5). More importantly, the dearomatization-aromatization process from 2 to 3 and from 3 to $\mathbf{4}$ leads to the migration of the metallaaromatic conformation. As shown in Fig. 5a, the insertion of an additional coordinating nitrogen atom results in the original metallapentalene unit in $\mathbf{2}$ (rings $\mathbf{a}$ and $\mathbf{b}$ ) rearranging to different positions in the metallacyclic systems in $\mathbf{4}$ and $\mathbf{5}$ (rings $\mathbf{b}$ and $\mathbf{c}$ ). Such an extraordinary shift in the aromatic units has never been observed in metallacyclic species.

Properties of chelates with N/C coordination environments. Previous studies have found that the incorporation of nitrogen and carbon atoms into a polydentate ligand framework significantly influences the optical and electronic properties of the resulting complex, highlighting the potential applications of these species in the fields of biomedical and optoelectronic materials ${ }^{7,10,11,13}$. We therefore embarked on photophysical studies on four structurally well-defined polydentate chelates, 2, 3, 4, and 5. The ultraviolet/visible (UV/Vis) absorption spectra of N/
C-based $\pi$ systems $\mathbf{2 - 5}$ are summarized in Fig. 6a. These complexes each exhibit a broad absorption band ranging from the UV to the Vis region and extending into the near-infrared (NIR) region. Considering the low-energy absorption bands, the absorption maximum of NCCCN core complex 5 in the Vis region $\left(\lambda_{\max }=669 \mathrm{~nm}\right)$ is redshifted by $194 \mathrm{~nm}$ compared with that of CCCCN core complex $2\left(\lambda_{\max }=475 \mathrm{~nm}\right)$. The absorption peaks of non-aromatic NCCC complex $3(\lambda=409 \mathrm{~nm}, \varepsilon=7.52 \times$ $10^{3} \mathrm{M}^{-1} \mathrm{~cm}^{-1}$ and $\left.\lambda=754 \mathrm{~nm}, \varepsilon=1.28 \times 10^{3} \mathrm{M}^{-1} \mathrm{~cm}^{-1}\right)$ are similar to those of aromatic NCCC complex $4(\lambda=422 \mathrm{~nm}, \varepsilon=$ $9.57 \times 10^{3} \mathrm{M}^{-1} \mathrm{~cm}^{-1}$ and $\left.\lambda=726 \mathrm{~nm}, \varepsilon=2.24 \times 10^{3} \mathrm{M}^{-1} \mathrm{~cm}^{-1}\right)$, but with a much smaller molar absorption coefficients, most likely due to its localized structure.

In particular, the effective low-energy absorptions of complexes 4 and $\mathbf{5}$ motivated us to study PA imaging properties ${ }^{45,46}$ of these metallaaromatic compounds. PA imaging is an emerging noninvasive molecular imaging technique based on the PA effect, which refers to the generation of acoustic waves due to thermal expansion following the absorption of light by absorbers. Compared with traditional optical imaging methods, PA imaging while retaining high spatial resolution remarkably enhances the penetration depth. A number of contrast agents, such as small molecule organic dyes, fluorescent proteins, metallic nanoparticles, organic nanoparticles, carbon nanotubes, 2D graphene analogs, porphysomes, and a few organometallic materials ${ }^{47-49}$, have been exploited in PA imaging. PA imaging of complexes 4 and 5 were performed in vitro using a PA instrument at $\lambda=700$ $\mathrm{nm}$. As shown in Fig. 6b, as expected, the PA signal increased with increasing concentrations of $\mathbf{4}$ and 5. NCCCN core complex 5 exhibits a stronger PA signal than NCCC core complex $\mathbf{4}$, which is probably due to the higher absorptivity of $\mathbf{5}$ compared to that of 4 at $\lambda=700 \mathrm{~nm}$. Due to the relatively strong absorption of 4 at $808 \mathrm{~nm}$, the photothermal effect $^{50}$ was also examined by measuring the temperature increase in solution of $\mathbf{4}$ at various concentrations in water-ethanol $(90 \% \mathrm{v} / \mathrm{v})$ solutions under NIR laser $\left(808 \mathrm{~nm}, 1 \mathrm{~W} \mathrm{~cm}^{-2}\right)$ irradiation. As shown in
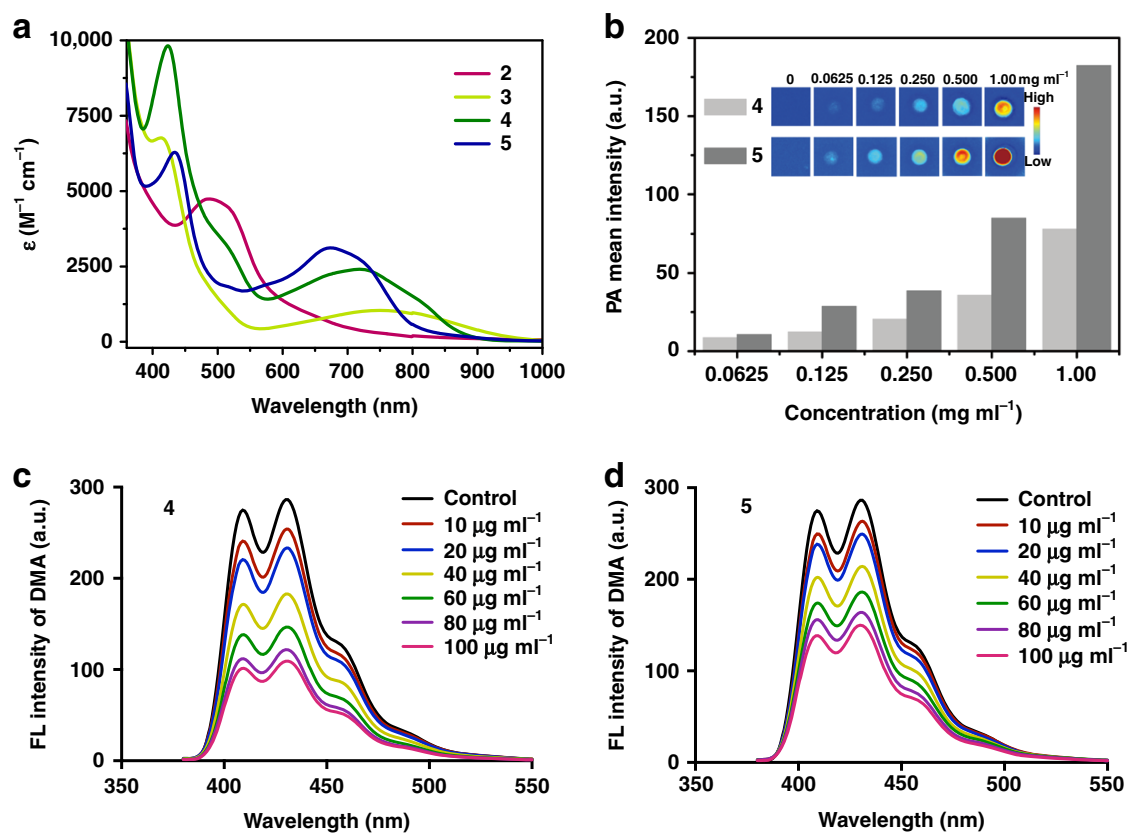

Fig. 6 Properties of chelates with $\mathrm{N} / \mathrm{C}$ coordination environments. a Ultraviolet-visible (UV-vis) absorption spectra of complexes 2-5 measured in $\mathrm{CH}_{2} \mathrm{Cl}_{2}$ at room temperature. $\mathbf{b}$ Photoacoustic (PA) mean intensities of $\mathbf{4}$ and $\mathbf{5}$ at different concentrations $\left(0.0625,0.125,0.250,0.500\right.$, and $\left.1.00 \mathrm{mg} \mathrm{ml}^{-1}\right)$ in MeCN monitored at $\lambda=700 \mathrm{~nm}$ (Inset: PA imaging). c, d Assessment of the generation of reactive oxygen species (ROS) by $\mathbf{4}$ and $\mathbf{5}$ at different concentrations (10, 20,40,60,80, and $100 \mu \mathrm{g} \mathrm{ml}^{-1}$ in $\left.\mathrm{CH}_{2} \mathrm{Cl}_{2}\right)$ when activated by ultrasound (US) $\left(1 \mathrm{MHz}, 0.56 \mathrm{~W} \mathrm{~cm}{ }^{-2}, 50 \% \mathrm{cycle}, 5 \mathrm{~min}\right)$. FL: fluorescence; DMA: 9,10-dimethylanthracene 
Supplementary Figure 16, with increasing concentration of $\mathbf{4}$, significant temperature increases were observed under laser irradiation. The solution containing $0.500 \mathrm{mg} \mathrm{ml}^{-1}$ of 4 exhibits a significant temperature increase from 32 to $78^{\circ} \mathrm{C}$ within 5 min.

The unique $\pi$-conjugated structures of complexes $\mathbf{4}$ and $\mathbf{5}$ motivated us to further investigate their potential applicability as sonosensitizers in sonodynamic therapy (SDT). SDT employs US to activate sonosensitizers to generate reactive oxygen species (ROS), which are cytotoxic and can be used to suppress the growth of tumors and pathogenic bacteria. Various organic and inorganic sonosensitizers have been adopted for SDT ${ }^{51-53}$. However, to the best of our knowledge, the study of sonodynamic effects based on organometallics has never been reported. Since ROS generation plays a critical role in determining the therapeutic efficacy of SDT, the ability of the complexes to generate ROS was therefore investigated. As shown in Fig. 6c, d, with increasing concentration, the fluorescence (FL) intensity of 9,10-dimethylanthracene (DMA) decreased, indicating that complexes $\mathbf{4}$ and $\mathbf{5}$ had the ability to generate ROS under ultrasound. Combined with their good performance of PA imaging, aromatic NCCC complex 4 and NCCCN complex $\mathbf{5}$ can be regarded as potential theranostic agents for PA imaging-guided SDT.

In summary, we have synthesized a series of planar, highcoordinate N/C complexes from reactions of CCCC tetradentate precursors. The pentadentate chelates have now been extended to the equatorial N/C joint coordination environment to build pentadentate complexes with CCCCN and NCCCN cores. Our studies revealed that the key to the success of this approach is the rich reactivity of the carbon-based ligands in accordance with the inherent aromaticity of the polycyclic metallaaromatic structures. Furthermore, the direct transfer of coordinating atoms in highcoordinate complexes allows a number of exceptional transformations, such as the migration of the metallaaromatic unit within the polycyclic system, the alteration of the aromatic ring skeleton, and the modification of the aromaticity of the aza-metallacyclic rings. Our findings provide a valuable supplement to the dearth of information available regarding high-coordinate complexes and hint at efficient route towards pentadentate complexes with N/C joint coordination sites. The unique examples reported herein exhibit significant sonodynamic effects and good PA performances, demonstrating their promise as theranostic agents for PA imaging-guided SDT for cancer or bacterial therapies.

\footnotetext{
Methods

General methods. All syntheses were carried out under an inert atmosphere $\left(\mathrm{N}_{2}\right)$ by means of standard Schlenk techniques, unless otherwise stated. Solvents were distilled from sodium/benzophenone (hexane and diethyl ether) or calcium hydride (dichloromethane) under $\mathrm{N}_{2}$ prior to use. Reagents were used as received from commercial sources without further purification. NMR spectroscopic experiments were performed on a Bruker Ascend 600 spectrometer $\left({ }^{1} \mathrm{H}, 600.1\right.$ $\left.\mathrm{MHz} ;{ }^{13} \mathrm{C}, 150.9 \mathrm{MHz} ;{ }^{31} \mathrm{P}, 242.9 \mathrm{MHz}\right)$ at room temperature and a Bruker AV-500 spectrometer $\left({ }^{1} \mathrm{H}, 500.2 \mathrm{MHz} ;{ }^{13} \mathrm{C}, 125.8 \mathrm{MHz} ;{ }^{31} \mathrm{P}, 202.5 \mathrm{MHz}\right)$ at room temperature. ${ }^{1} \mathrm{H}$ and ${ }^{13} \mathrm{C}$ NMR chemical shifts $(\delta)$ are relative to tetramethylsilane, and ${ }^{31} \mathrm{P}$ NMR chemical shifts are relative to $85 \% \mathrm{H}_{3} \mathrm{PO}_{4}$. The absolute values of the coupling constants are given in hertz $(\mathrm{Hz})$. Multiplicities are abbreviated as singlet $(\mathrm{s})$, doublet $(\mathrm{d})$, triplet $(\mathrm{t})$, multiplet $(\mathrm{m})$, quartet $(\mathrm{q})$, and broad (br). The highresolution mass spectrometry (HRMS) data were recorded on a Bruker En Apex Ultra 7.0 T FT-MS. The theoretical molecular ion peak was calculated by Compass Isotope Pattern software supplied by Bruker Co. For the HRMS, ${ }^{1} \mathrm{H},{ }^{31} \mathrm{P} \mathrm{NMR}$, and ${ }^{13} \mathrm{C}$ NMR spectra of the complexes in this article, see Supplementary Figures 17 32. Elemental analysis data were obtained on an Elementar Analysensysteme GmbH Vario EL III instrument. The UV/Vis/NIR spectra of complexes 2, 3, 4, and 5 were recorded with a Varian Cary5000 UV/Vis spectrophotometer.
}

Synthesis of the starting material 1. According to a previously published procedure $^{30}$, allenylboronic acid pinacol ester $(144 \mu \mathrm{l}, 0.80 \mathrm{mmol})$ was added to a suspension of $\left[\mathrm{OsCl}_{2}\left(\mathrm{CHC}\left(\mathrm{PPh}_{3}\right) \mathrm{CH}(\mathrm{OH}) \mathrm{C} \equiv \mathrm{CH}\right)\left(\mathrm{PPh}_{3}\right)_{2}\right](300 \mathrm{mg}, 0.27 \mathrm{mmol})$ in dichloromethane $(15 \mathrm{ml})$. The mixture was stirred at room temperature (RT) for $30 \mathrm{~min}$ to give a yellow solution. The solution was evaporated under vacuum to a volume of ca. $2 \mathrm{ml}$, then diethyl ether $(20 \mathrm{ml})$ was added to the solution. The yellow precipitate was collected by filtration, washed with diethyl ether $(2 \times 5 \mathrm{ml})$ and dried under vacuum to give $\mathbf{1}(275 \mathrm{mg}, 89 \%)$ as a yellow solid.

Synthesis of the complex with a CCCCN-core (2). A mixture of 1 (200 mg, 0.174 $\mathrm{mmol}), 2$-ethynylpyridine $(52 \mu \mathrm{l}, 0.522 \mathrm{mmol})$, and silver perchlorate $(144 \mathrm{mg}$, $0.696 \mathrm{mmol})$ in dichloromethane/methanol $(9 / 3 \mathrm{ml})$ was stirred at $60^{\circ} \mathrm{C}$ in a sealed Schlenk tube for $1 \mathrm{~h}$ to give an amaranthine solution. The silver chloride precipitate was removed by filtration, and the filtrate was concentrated under vacuum to $\sim 2 \mathrm{ml}$ of residue. The residue was washed with $\mathrm{Et}_{2} \mathrm{O}(2 \times 15 \mathrm{ml})$ to give 2 as an amaranthine solid. Yield: $223 \mathrm{mg}, 92 \%$. Diagnostic peaks for 2 are as follows: ${ }^{1} \mathrm{H}$ NMR plus ${ }^{1} \mathrm{H}-{ }^{13} \mathrm{C}$ HSQC $\left(600.1 \mathrm{MHz}, \mathrm{CD}_{2} \mathrm{Cl}_{2}\right): \delta=14.2\left(\mathrm{~d},{ }^{3} J_{\mathrm{HP}}=14.3 \mathrm{~Hz}, 1 \mathrm{H}, \mathrm{C}^{1} \mathrm{H}\right)$, $9.7\left(\mathrm{~d},{ }^{4} J_{\mathrm{HP}}=3.6 \mathrm{~Hz}, 1 \mathrm{H}, \mathrm{C}^{5} \mathrm{H}\right), 9.1\left(\mathrm{dd},{ }^{3} J_{\mathrm{HP}}=3.8 \mathrm{~Hz},{ }^{4} J_{\mathrm{PH}}=2.3 \mathrm{~Hz}, 1 \mathrm{H}, \mathrm{C}^{3} \mathrm{H}\right)$, $8.8\left(\mathrm{~d},{ }^{3} \mathrm{~J}_{\mathrm{HH}}=5.3 \mathrm{~Hz}, 1 \mathrm{H}, \mathrm{C}^{15} \mathrm{H}\right), 8.1\left(\mathrm{~m}, 1 \mathrm{H}, \mathrm{C}^{6} \mathrm{H}\right), 7.7-6.6(48 \mathrm{H}$, other aromatic protons), $6.5 \mathrm{ppm}\left(\mathrm{d},{ }^{4} J_{\mathrm{HP}}=7.6 \mathrm{~Hz}, 1 \mathrm{H}, \mathrm{C}^{9} \mathrm{H}\right) .{ }^{31} \mathrm{P} \mathrm{NMR}\left(242.9 \mathrm{MHz}, \mathrm{CD}_{2} \mathrm{Cl}_{2}\right)$ : $\delta=12.1\left(\mathrm{~s}, \mathrm{CPPh} \mathrm{P}_{3}\right),-8.6 \mathrm{ppm}\left(\mathrm{s},{\mathrm{Os} P P \mathrm{P}_{3}}\right) .{ }^{13} \mathrm{C} \mathrm{NMR}$ plus ${ }^{1} \mathrm{H}-{ }^{13} \mathrm{C} \mathrm{HMBC}$ and ${ }^{1} \mathrm{H}-$ ${ }^{13} \mathrm{C}$ HSQC (150.9 MHz, $\left.\mathrm{CD}_{2} \mathrm{Cl}_{2}\right): \delta=232.4$ (br, C1), $220.9\left(\mathrm{t},{ }^{2} J_{\mathrm{CP}}=9.0 \mathrm{~Hz}, \mathrm{C} 7\right)$, 206.9 (s, C8), $198.4\left(\mathrm{dt},{ }^{2} J_{\mathrm{CP}}=23.5 \mathrm{~Hz},{ }^{3} J_{\mathrm{CP}}=3.7 \mathrm{~Hz}, \mathrm{C} 4\right), 169.6$ (s, C5), 168.9 (s, $\mathrm{C} 11), 166.7\left(\mathrm{~d},{ }^{2} J_{\mathrm{CP}}=20.4 \mathrm{~Hz}, \mathrm{C} 3\right), 162.5\left(\mathrm{t},{ }^{2} J_{\mathrm{CP}}=7.8 \mathrm{~Hz}, \mathrm{C} 10\right), 157.0(\mathrm{~s}, \mathrm{C} 6)$, 145.0 (s, C15), $141.6\left(\mathrm{~d},{ }^{1} J_{\mathrm{PC}}=70.4 \mathrm{~Hz}, \mathrm{C} 2\right), 119.8$ (s, C9), 140.7-116.6 ppm (other aromatic carbons and the above-mentioned $\mathrm{C} 9$ ). Elemental analysis calcd (\%) for $\mathrm{C}_{69} \mathrm{H}_{54} \mathrm{Cl}_{2} \mathrm{NO}_{9} \mathrm{OsP}_{3}$ : C 59.40, $\mathrm{H} 3.90, \mathrm{~N} 1.00$; found: C 59.19, H 4.03, N 1.36 HRMS (ESI): $m / z$ calcd for $\left[\mathrm{C}_{69} \mathrm{H}_{54} \mathrm{NOOsP}_{3}\right]^{2+}$, 598.6515; found, 598.6529.

Synthesis of the complex with an NCCC-core (3). A mixture of 2 (200 mg, 0.143 $\mathrm{mmol})$ and azidotrimethylsilane $(94 \mu \mathrm{l}, 0.72 \mathrm{mmol})$ was stirred at room temperature for $12 \mathrm{~h}$ to give a green solution. Then, $n$ - $\mathrm{Bu}_{4} \mathrm{NF}\left(0.72 \mathrm{ml}, 1.0 \mathrm{moll}^{-1}\right.$ in tetrahydrofuran, $0.72 \mathrm{mmol}$ ) was added to the solution. The mixture was stirred at room temperature for $1 \mathrm{~h}$ and then concentrated under vacuum to $\sim 2 \mathrm{ml}$. The residue was purified by column chromatography (neutral alumina, eluent: dichloromethane/methanol $=20: 1$ ) to give a green solution. The solvent was evaporated to under vacuum to give $\sim 2 \mathrm{ml}$ of residue, which was then washed with $\mathrm{Et}_{2} \mathrm{O}(2 \times 15 \mathrm{ml})$ to give 3 as a green solid. Yield: $107 \mathrm{mg}, 57 \%$. Diagnostic peaks for 3 are as follows: ${ }^{1} \mathrm{H}$ NMR plus ${ }^{1} \mathrm{H}-{ }^{13} \mathrm{C}$ HSQC $\left(500.2 \mathrm{MHz}, \mathrm{CD}_{2} \mathrm{Cl}_{2}\right): \delta=8.5(\mathrm{~d}$, $\left.{ }^{3} J_{\mathrm{HH}}=3.6 \mathrm{~Hz}, 1 \mathrm{H}, \mathrm{C}^{15} \mathrm{H}\right), 7.5\left(\mathrm{~s}, 1 \mathrm{H}, \mathrm{C}^{6} \mathrm{H}\right), 7.4\left(\mathrm{~s}, 1 \mathrm{H}, \mathrm{C}^{9} H\right), 7.8-6.9(49 \mathrm{H}$, other aromatic protons and the above-mentioned $\mathrm{C}^{6} \mathrm{H}$ and $\left.\mathrm{C}^{9} \mathrm{H}\right), 6.5\left(\mathrm{~d},{ }^{3} J_{\mathrm{HH}}=8.1 \mathrm{~Hz}\right.$, $\left.1 \mathrm{H}, \mathrm{C}^{12} \mathrm{H}\right), 5.9\left(\mathrm{~s}, 1 \mathrm{H}, \mathrm{C}^{3} H\right), 5.4\left(\mathrm{~s}, 1 \mathrm{H}, \mathrm{C}^{5} \mathrm{H}\right), 4.5 \mathrm{ppm}\left(\mathrm{d},{ }^{3} J_{\mathrm{PH}}=15.9 \mathrm{~Hz}, 1 \mathrm{H}\right.$, $\left.\mathrm{C}^{1} H\right) .{ }^{31} \mathrm{P}$ NMR $\left(202.5 \mathrm{MHz}, \mathrm{CD}_{2} \mathrm{Cl}_{2}\right): \delta=18.0(\mathrm{~s}, \mathrm{CPPh}), 3.0 \mathrm{ppm}\left(\mathrm{s}, \mathrm{Os}_{3} \mathrm{Ph}_{3}\right)$. ${ }^{13} \mathrm{C}$ NMR plus ${ }^{1} \mathrm{H}-{ }^{13} \mathrm{C} \mathrm{HMBC}$ and ${ }^{1} \mathrm{H}-{ }^{13} \mathrm{C} \mathrm{HSQC}\left(125.8 \mathrm{MHz}, \mathrm{CD}_{2} \mathrm{Cl}_{2}\right): \delta=218.8$ $\left(\mathrm{t},{ }^{2} J_{\mathrm{CP}}=7.6 \mathrm{~Hz}, \mathrm{C} 7\right), 197.0(\mathrm{br}, \mathrm{C} 10), 196.1(\mathrm{~s}, \mathrm{C} 8), 177.2\left(\mathrm{dt},{ }^{2} J_{\mathrm{CP}}=19.2 \mathrm{~Hz}\right.$, $\left.{ }^{3} J_{\mathrm{CP}}=9.1 \mathrm{~Hz}, \mathrm{C} 4\right), 166.1$ (br, C5), 164.5 (s, C11), $159.5\left(\mathrm{~d},{ }^{2} J_{\mathrm{CP}}=13.0 \mathrm{~Hz}, \mathrm{C} 1\right)$, 147.8 (s, C15), 142.4 (s, C9), 138.6 (s, C6), 137.5 (d, $\left.{ }^{2} J_{\mathrm{CP}}=15.6 \mathrm{~Hz}, \mathrm{C} 3\right), 119.2$ (s, $\mathrm{C} 12$ ), 136.3-117.3 (other aromatic carbons and the above-mentioned $\mathrm{C} 12$ ), $93.0 \mathrm{ppm}\left(\mathrm{d},{ }^{1} J_{\mathrm{PC}}=91.5 \mathrm{~Hz}, \mathrm{C} 2\right)$. Elemental analysis calcd (\%) for $\mathrm{C}_{69} \mathrm{H}_{54} \mathrm{ClN}_{2} \mathrm{O}_{5} \mathrm{OsP}_{3}$ : C 63.27, H 4.16, N 2.14; found: C 63.27, H 4.46, N 2.09 . HRMS (ESI): $m / z$ calcd for $\left[\mathrm{C}_{69} \mathrm{H}_{54} \mathrm{~N}_{2} \mathrm{OOsP}_{3}\right]^{+}, 1211.3065$; found, 1211.3034 .

Synthesis of the complex with an NCCC-core (4). A mixture of 3 (100 mg, 76.3 $\mu \mathrm{mol})$ and MeOTf $(8.6 \mu \mathrm{l}, 76.3 \mu \mathrm{mol})$ in dichloromethane $(10 \mathrm{ml})$ was stirred at room temperature for $15 \mathrm{~min}$ to give a green solution. The solvent was evaporated under vacuum to give $\sim 2 \mathrm{ml}$ of residue. The residue was washed with $\mathrm{Et}_{2} \mathrm{O}(2 \times$ $15 \mathrm{ml}$ ) to give 4 as a green solid. Yield: $102 \mathrm{mg}, 91 \%$. Diagnostic peaks for 4 are as follows: ${ }^{1} \mathrm{H}$ NMR plus ${ }^{1} \mathrm{H}_{-}{ }^{13} \mathrm{C}$ HSQC $\left(500.2 \mathrm{MHz}, \mathrm{CD}_{2} \mathrm{Cl}_{2}\right): \delta=8.9\left(\mathrm{~s}, 1 \mathrm{H}, \mathrm{C}^{15} \mathrm{H}\right)$, $8.8\left(\mathrm{~s}, 1 \mathrm{H}, \mathrm{C}^{6} \mathrm{H}\right), 8.3\left(\mathrm{~s}, 1 \mathrm{H}, \mathrm{C}^{9} H\right), 7.0\left(\mathrm{~s}, 1 \mathrm{H}, \mathrm{C}^{5} \mathrm{H}\right), 7.0\left(\mathrm{~s}, 1 \mathrm{H}, \mathrm{C}^{3} \mathrm{H}\right), 7.8-6.9(50 \mathrm{H}$, other aromatic protons and the above-mentioned $\mathrm{C}^{3} \mathrm{H}$ and $\left.\mathrm{C}^{5} \mathrm{H}\right), 5.6\left(\mathrm{~d},{ }^{3} \mathrm{~J}_{\mathrm{HP}}=\right.$ $\left.14.2 \mathrm{~Hz}, 1 \mathrm{H}, \mathrm{C}^{1} \mathrm{H}\right), 3.8 \mathrm{ppm}\left(\mathrm{s}, 3 \mathrm{H}, \mathrm{C}^{16} \mathrm{H}\right) .{ }^{31} \mathrm{P} \mathrm{NMR}\left(202.5 \mathrm{MHz}, \mathrm{CD}_{2} \mathrm{Cl}_{2}\right): \delta=$

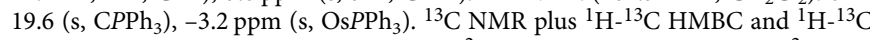
HSQC $\left(125.8 \mathrm{MHz}, \mathrm{CD}_{2} \mathrm{Cl}_{2}\right): \delta=248.3\left(\mathrm{t},{ }^{2} J_{\mathrm{CP}}=7.5 \mathrm{~Hz}, \mathrm{C10}\right), 193.4\left(\mathrm{dt},{ }^{2} J_{\mathrm{CP}}=\right.$ $\left.18.6 \mathrm{~Hz},{ }^{3} J_{\mathrm{CP}}=9.9 \mathrm{~Hz}, \mathrm{C} 4\right), 178.3$ (s, C7), 175.6 (s, C8), 163.7 (br, C5), 162.9 (s, C11), $156.3\left(\mathrm{~d},{ }^{2} J_{\mathrm{CP}}=12.9 \mathrm{~Hz}, \mathrm{C} 1\right), 150.0(\mathrm{~s}, \mathrm{C} 6), 149.8(\mathrm{~s}, \mathrm{C} 15), 140.3\left(\mathrm{~d},{ }^{2} J_{\mathrm{CP}}=\right.$ $15.7 \mathrm{~Hz}, \mathrm{C} 3$ ), 137.9 (s, C9), $121.0\left(\mathrm{q}, \mathrm{J}(\mathrm{F}, \mathrm{C})=317.7 \mathrm{~Hz}, \mathrm{CF}_{3} \mathrm{SO}_{3}\right.$ ), 137.2-116.0 (other aromatic carbons and the above-mentioned $\left.\mathrm{CF}_{3} \mathrm{SO}_{3}\right), 98.1\left(\mathrm{~d},{ }^{1} J_{\mathrm{CP}}=88.7 \mathrm{~Hz}, \mathrm{C} 2\right)$, $60.5 \mathrm{ppm}(\mathrm{s}, \mathrm{C} 16)$. Elemental analysis calcd (\%) for $\mathrm{C}_{71} \mathrm{H}_{57} \mathrm{ClF}_{3} \mathrm{~N}_{2} \mathrm{O}_{8} \mathrm{OsP} \mathrm{P}_{3} \mathrm{~S}: \mathrm{C} 57.86$, $\mathrm{H}$ 3.90, N 1.90; found: C 57.87, H 4.10, N 1.77. HRMS (ESI): $\mathrm{m} / z$ calcd for $\left[\mathrm{C}_{70} \mathrm{H}_{57} \mathrm{~N}_{2} \mathrm{OOsP}_{3}\right]^{2+}$, 613.1647; found, 613.1631.

Synthesis of the complex with an NCCCN-core (5). A mixture of 4 (100 mg $67.8 \mu \mathrm{mol})$ and perchloric acid $(29 \mu \mathrm{l}, 70 \mathrm{wt} \%)$ in dichloromethane $(10 \mathrm{ml})$ was stirred at room temperature for $1 \mathrm{~h}$ to give a deep green solution. The solvent was evaporated under vacuum to give $\sim 2 \mathrm{ml}$ of crude material. The residue was washed with $\mathrm{Et}_{2} \mathrm{O}(1 \times 15 \mathrm{ml})$ to give 5 as a deep green solid. Yield: $94 \mathrm{mg}, 88 \%$. Diagnostic peaks for 5 are as follows: ${ }^{1} \mathrm{H}$ NMR plus ${ }^{1} \mathrm{H}-{ }^{13} \mathrm{C} \mathrm{HSQC}\left(500.2 \mathrm{MHz}, \mathrm{CD}_{2} \mathrm{Cl}_{2}\right): \delta=$ $11.3\left(\mathrm{~d},{ }^{3} J_{\mathrm{HP}}=11.9 \mathrm{~Hz}, 1 \mathrm{H}, \mathrm{NH}\right), 9.3\left(\mathrm{dd},{ }^{3} J_{\mathrm{HP}}=11.6 \mathrm{~Hz},{ }^{4} J_{\mathrm{HP}}=5.3 \mathrm{~Hz}, 1 \mathrm{H}, \mathrm{C}^{1} H\right)$, $8.9\left(\mathrm{~d},{ }^{3} J_{\mathrm{HH}}=5.0 \mathrm{~Hz}, 1 \mathrm{H}, \mathrm{C}^{15} \mathrm{H}\right), 8.8\left(\mathrm{t},{ }^{4} J_{\mathrm{HP}}=1.9 \mathrm{~Hz}, 1 \mathrm{H}, \mathrm{C}^{9} \mathrm{H}\right), 8.4\left(\mathrm{~d},{ }^{4} J_{\mathrm{HP}}=3.4\right.$ $\left.\mathrm{Hz}, 1 \mathrm{H}, \mathrm{C}^{6} \mathrm{H}\right), 8.3\left(\mathrm{dd},{ }^{4} J_{\mathrm{HP}}=6.2 \mathrm{~Hz},{ }^{4} J_{\mathrm{HP}}=3.2 \mathrm{~Hz}, 1 \mathrm{H}, \mathrm{C}^{5} \mathrm{H}\right), 7.6\left(\mathrm{~d},{ }^{3} J_{\mathrm{HP}}=11.6\right.$ $\left.\mathrm{Hz},{ }^{4} J_{\mathrm{HP}}=3.7 \mathrm{~Hz}, 1 \mathrm{H}, \mathrm{C}^{3} \mathrm{H}\right), 6.7-7.9(49 \mathrm{H}$, other aromatic protons and the abovementioned $\left.\mathrm{C}^{3} \mathrm{H}\right), 4.0 \mathrm{ppm}\left(\mathrm{s}, 3 \mathrm{H}, \mathrm{C}^{16} \mathrm{H}\right) .{ }^{31} \mathrm{P} \mathrm{NMR}\left(202.5 \mathrm{MHz}, \mathrm{CD}_{2} \mathrm{Cl}_{2}\right): \delta=22.3$ $\left(\mathrm{s}, \mathrm{CPPh}\right.$ ), $-14.2 \mathrm{ppm}\left(\mathrm{s}, \mathrm{Os} P \mathrm{Ph}_{3}\right) .{ }^{13} \mathrm{C}$ NMR plus ${ }^{1} \mathrm{H}_{-}{ }^{13} \mathrm{C} \mathrm{HMBC}$ and ${ }^{1} \mathrm{H}_{-}{ }^{13} \mathrm{C}$ HSQC (125.8 MHz, $\mathrm{CD}_{2} \mathrm{Cl}_{2}$ ): $\delta=189.4$ (s, C10), 185.6 (s, C8), 184.8 (m, C4), 183.4 
(m, C7), 175.3 (s, C5), 165.8 (s, C11), 165.5 (d, $\left.{ }^{2} J_{\mathrm{CP}}=17.6 \mathrm{~Hz}, \mathrm{C1}\right), 161.7$ (d, $\left.{ }^{2} J_{\mathrm{CP}}=7.9 \mathrm{~Hz}, \mathrm{C} 3\right), 155.1$ (s, C6), 143.6 (s, C15), 132.4 (s, C9), 119.9 (q, J(F,C) = $317.4 \mathrm{~Hz}, \mathrm{CF}_{3} \mathrm{SO}_{3}$ ), 141.8-114.1 (other aromatic carbons and the above-mentioned $\mathrm{C} 9$ and $\left.\mathrm{CF}_{3} \mathrm{SO}_{3}\right), 109.1\left(\mathrm{~d},{ }^{1} J_{\mathrm{CP}}=97.4 \mathrm{~Hz}, \mathrm{C} 2\right), 62.6 \mathrm{ppm}(\mathrm{s}, \mathrm{C} 16)$. Elemental analysis calcd (\%) for $\mathrm{C}_{71} \mathrm{H}_{58} \mathrm{Cl}_{2} \mathrm{~F}_{3} \mathrm{~N}_{2} \mathrm{O}_{12} \mathrm{OsP}_{3} \mathrm{~S}$ : C 54.17, $\mathrm{H} 3.71, \mathrm{~N} 1.78$; found: $\mathrm{C}$ 54.20, $\mathrm{H}$ 3.97, $\mathrm{N}$ 1.43. HRMS (ESI): $\mathrm{m} / z$ calcd for $\left[\mathrm{C}_{70} \mathrm{H}_{58} \mathrm{~N}_{2} \mathrm{OOsP}_{3}{ }^{3+}-\mathrm{H}^{+}\right]^{2+}$, 613.1647; found, 613.1663

PA imaging. Solutions of $\mathbf{4}$ and $\mathbf{5}$ at different concentrations in $\mathrm{MeCN}$ were stored in $0.2-\mathrm{ml}$ transparent plastic vials. Then, PA images of $\mathbf{4}$ and $\mathbf{5}$ were obtained at $700 \mathrm{~nm}$ using a PA system (Endra Nexus 128, Ann Arbor, MI, USA).

Photothermal effect. Solutions of complex 4 at different concentrations in $1 \mathrm{ml}$ of $10 \%$ ethanol- $\mathrm{H}_{2} \mathrm{O}$ were placed in transparent plastic vials. Then, the solutions were irradiated with an $808 \mathrm{~nm}$ laser at a power density of $1 \mathrm{~W} \mathrm{~cm}^{-2}$ for $10 \mathrm{~min}$. The temperature was monitored by a digital thermometer. The real-time temperature changes were recorded by a FLIR Ax 5 thermal camera.

Assessment of ROS generation by $\mathbf{4 / 5}$ upon sono-activation. The production of ROS was examined based on the decrease in the FL of DMA, an ROS sensor. Solutions of $\mathbf{4}$ and $\mathbf{5}$ in DCM were prepared at different concentrations. DMA was then added to give a final concentration of $20 \mu \mathrm{M}$. Each sample was exposed to ultrasound $\left(1 \mathrm{MHz}, 0.56 \mathrm{Wcm}^{-2}, 50 \%\right.$ cycle, $\left.5 \mathrm{~min}\right)$. The FL intensity of the DMA was detected at and excitation wavelength of $360 \mathrm{~nm}$ and an emission range of $380-550 \mathrm{~nm}$.

Computational details. All structures were optimized at the B3LYP level of DFT $^{54-56}$ with the PCM solvation method in dichloromethane. Additionally, frequency calculations were performed to confirm that the energies of the calculated structures were at minima (zero imaginary frequency) or transition states (one imaginary frequency), and to provide Gibbs free energies at $298.15 \mathrm{~K}$. In the B3LYP calculations, the effective core potentials given by Hay and Wadt with a double- $\zeta$ valence basis set $(\mathrm{LanL} 2 \mathrm{DZ})^{57}$ were used to describe the $\mathrm{Os}, \mathrm{Cl}, \mathrm{Si}$, and $\mathrm{P}$ atoms, whereas the standard 6-311++ $\mathrm{G}^{* *}$ basis set was used for the $\mathrm{C}, \mathrm{N}, \mathrm{O}$, and $\mathrm{H}$ atoms for all the model compounds in the ASE, NICS, ACID, and Wiberg bond index calculations. For the mechanism study, we used the original structures without changing the $\mathrm{PPh}_{3}$ groups to $\mathrm{PH}_{3}$ groups to obtain a more reasonable estimation of the energy differences. All of these structures evaluated were optimized at the standard 6-31 $\mathrm{G}^{*}$ basis set for $\mathrm{C}, \mathrm{N}, \mathrm{O}$, and $\mathrm{H}$ atoms. Intrinsic reaction coordinate calculations were also calculated for the transition state to confirm that such structure indeed connected two relevant minima ${ }^{58}$. Polarization functions were added for Os $(\zeta(\mathrm{f})=0.886), \mathrm{Cl}(\zeta(\mathrm{d})=0.514), \mathrm{Si}(\zeta(\mathrm{d})=0.262)$, and $\mathrm{P}(\zeta(\mathrm{d})=$ $0.340)^{59}$ in all calculations. All optimizations were performed with the Gaussian 09 software package ${ }^{60}$. Wiberg bond index ${ }^{61}$ calculations were carried out with the NBO 6.0 program $^{62}$ interfaced with the Gaussian 09 program. (NICS) ${ }^{37-39}$ values were calculated at the B3LYP-GIAO/6-311++ $\mathrm{G}^{* *}$ level of theory. The ACID calculations were carried out with the ACID program ${ }^{40,41}$

X-ray crystallographic analysis. Crystals suitable for X-ray diffraction were grown from a dichloroethane solution (for 2) or a dichloromethane solution (for $\mathbf{3}$, 4, and 5) layered with hexane. Single-crystal X-ray diffraction data were collected on an Oxford Gemini S Ultra CCD area detector with graphite-monochromated Mo Ka radiation $(\lambda=0.71073 \AA$ ) for $\mathbf{2 , 4}$, and 5. An Agilent SuperNova Dual system with mirror-monochromated Mo Ka radiation $(\lambda=0.71073 \AA$ ) was used for 3. Using Olex $2^{63}$, the structures were solved using the SHELXT ${ }^{64}$ structure solution program using the intrinsic phasing method $(\mathbf{2}, \mathbf{3}, \mathbf{4}$, and $\mathbf{5})$, and all of the structures were refined with the SHELXL ${ }^{65}$ refinement package using least-squares minimization. All non-hydrogen atoms were refined anisotropically, unless otherwise stated. The hydrogen atoms were placed at their idealized positions and assumed the riding model, unless otherwise stated. The water $\left(\mathrm{H}_{2} \mathrm{O}\right)$ and dichloromethane $\left(\mathrm{CH}_{2} \mathrm{Cl}_{2}\right)$ solvent molecules in $\mathbf{4}$ were refined without the addition of $\mathrm{H}$ atoms. For further details on the crystal data, data collection, refinements, and response to the questions raised in the Check CIF Reports, see Supplementary Table 1 and Supplementary Table 2 .

\section{Data availability}

The authors declare that the main data supporting the findings of this study are available within the article and its Supplementary Information file and Supplementary Data file. Crystallographic data are available through the Cambridge Crystallographic Data Center: CCDC identifiers are CCDC 1869552 (complex 2), CCDC 1869553 (complex 3), CCDC 1869554 (complex 4), and CCDC 1869556 (complex 5). Extra data are available from the corresponding author upon request.

Received: 26 September 2018 Accepted: 8 March 2019

Published online: 02 April 2019

\section{References}

1. Kettle, S. F. A Physical Inorganic Chemistry: A Coordination Chemistry Approach (Springer, Berlin, Heidelberg, 1996).

2. Lawrance, G. A. Introduction to Coordination Chemistry (Wiley, Chippenham, 2009).

3. Cook, T. R. \& Stang, P. J. Recent developments in the preparation and chemistry of metallacycles and metallacages via coordination. Chem. Rev. 115, 7001-7045 (2015)

4. Lu, H. J. \& Zhang, X. P. Catalytic C-H functionalization by metalloporphyrins: recent developments and future directions. Chem. Soc. Rev. 40, 1899-1909 (2011).

5. Choi, J. et al. Net oxidative addition of $\mathrm{C}\left(\mathrm{sp}^{3}\right)-\mathrm{F}$ bonds to iridium via initial C-H bond activation. Science 332, 1545-1548 (2011).

6. Desguin, B. et al. A tethered niacin-derived pincer complex with a nickelcarbon bond in lactate racemase. Science 349, 66-69 (2015).

7. Liu, L., Wang, X., Wang, N., Peng, T. \& Wang, S. Bright, multi-responsive, sky-blue platinum(II) phosphors based on a tetradentate chelating framework. Angew. Chem. Int. Ed. 56, 9160-9164 (2017).

8. Thoi, V. S., Kornienko, N., Margarit, C. G., Yang, P. \& Chang, C. J. Visiblelight photoredox catalysis: selective reduction of carbon dioxide to carbon monoxide by a nickel $\mathrm{N}$-heterocyclic carbene-isoquinoline complex. J. Am. Chem. Soc. 135, 14413-14424 (2013).

9. Izawa, M. et al. Möbius aromatic 28 hexaphyrin Germanium(IV) and Tin(IV) complexes: efficient formation of triplet excited states. Angew. Chem. Int. Ed. 56, 3982-3986 (2017).

10. Chow, P.-K. et al. Highly luminescent palladium(ii) complexes with submillisecond blue to green phosphorescent excited states. Photocatalysis and highly efficient PSF-OLEDs. Chem. Sci. 7, 6083-6098 (2016).

11. Cutillas, N. et al. Anticancer cyclometalated complexes of platinum group metals and gold. Coord. Chem. Rev. 257, 2784-2797 (2013).

12. Cheng, J., Wang, L., Wang, P. \& Deng, L. High-oxidation-state $3 \mathrm{~d}$ metal (Ti-Cu) complexes with N-heterocyclic carbene ligation. Chem. Rev. 118, 9930-9987 (2018)

13. Mills, I. N., Porras, J. A. \& Bernhard, S. Judicious design of cationic, cyclometalated $\operatorname{Ir}(\mathrm{III})$ complexes for photochemical energy conversion and optoelectronics. Acc. Chem. Res. 51, 352-364 (2018).

14. Liu, B. et al. Osmapyridine and osmapyridinium from a formal $4+2$ cycloaddition reaction. Angew. Chem. Int. Ed. 48, 5430-5434 (2009).

15. Albrecht, M., Lutz, M., Spek, A. L. \& van Koten, G. Organoplatinum crystals for gas-triggered switches. Nature 406, 970-974 (2000).

16. O’Reilly, M. E. \& Veige, A. S. Trianionic pincer and pincer-type metal complexes and catalysts. Chem. Soc. Rev. 43, 6325-6369 (2014).

17. Rpsca, D.-A., Wright, J. A., Hughes, D. L. \& Bochmann, M. Gold peroxide complexes and the conversion of hydroperoxides into gold hydrides by successive oxygen-transfer reactions. Nat. Commun. 4, 2167 (2013).

18. Dalebrook, A. F. \& Wright, L. J. Annulation of an iridabenzene through formal cycloaddition reactions with organonitriles. Organometallics 28, 5536-5540 (2009).

19. Szyszko, B. \& Latos-Grażyński, L. Core chemistry and skeletal rearrangements of porphyrinoids and metalloporphyrinoids. Chem. Soc. Rev. 44, 3588-3616 (2015).

20. Lash, T. D. Carbaporphyrinoid systems. Chem. Rev. 117, 2313-2446 (2017).

21. Maurya, Y. K. et al. Ground-state copper(III) stabilized by N-confused/Nlinked corroles: synthesis, characterization, and redox reactivity. J. Am. Chem. Soc. 140, 6883-6892 (2018).

22. Ke, X.-S., Hong, Y., Lynch, V. M., Kim, D. \& Sessler, J. L. Metal-stabilized quinoidal dibenzo[ $g$, $p]$ chrysene-fused bis-dicarbacorrole system. J. Am. Chem. Soc. 140, 7579-7586 (2018).

23. Zhu, C. et al. Stabilization of anti-aromatic and strained five-membered rings with a transition metal. Nat. Chem. 5, 698-703 (2013).

24. Wei, J. N. et al. Aromatic dicupra 10 annulenes. J. Am. Chem. Soc. 138, 60-63 (2016).

25. Wright, L. J. Metallabenzenes: An Expert View (Wiley, Oxford, 2017).

26. Frogley, B. J. \& Wright, L. J. A metallaanthracene and derived metallaanthraquinone. Angew. Chem. Int. Ed. 56, 143-147 (2017).

27. Zhang, Y. L. et al. Spiro metalla-aromatics of Pd, Pt, and Rh: synthesis and characterization. J. Am. Chem. Soc. 139, 5039-5042 (2017).

28. Zhuo, Q. et al. Multiyne chains chelating osmium via three metal-carbon $\sigma$ bonds. Nat. Commun. 8, 1912 (2017).

29. Zhu, C. \& Xia, H. Carbolong chemistry: a story of carbon chain ligands and transition metals. Acc. Chem. Res. 51, 1691-1700 (2018).

30. Zhu, C. et al. $\sigma$-Aromaticity in an unsaturated ring: osmapentalene derivatives containing a metallacyclopropene unit. Angew. Chem. Int. Ed. 54, 3102-3106 (2015).

31. Zhu, C. et al. CCCCC pentadentate chelates with planar Möbius aromaticity and unique properties. Sci. Adv. 2, e1601031 (2016).

32. Zhu, C. et al. Synthesis and characterization of a metallacyclic framework with three fused five-membered rings. Angew. Chem. Int. Ed. 56, 9067-9071 (2017) 
33. Zhu, C. et al. Planar Möbius aromatic pentalenes incorporating 16 and 18 valence electron osmiums. Nat. Commun. 5, 3265 (2014).

34. Gavey, E. L. \& Pilkington, M. Coordination complexes of 15-membered pentadentate aza, oxoaza and thiaaza Schiff base macrocycles "Old Complexes Offer New Attractions”. Coord. Chem. Rev. 296, 125-152 (2015).

35. Wang, T. et al. Synthesis and characterization of a metallapyridyne complex. Angew. Chem. Int. Ed. 51, 9838-9841 (2012).

36. Weller, K. J., Filippov, I., Briggs, P. M. \& Wigley, D. E. Pyridine degradation intermediates as models for hydrodenitrogenation catalysis: preparation and properties of a metallapyridine complex. Organometallics 17, 322-329 (1998).

37. Schleyer, Pv. R., Maerker, C., Dransfeld, A., Jiao, H. \& Hommes, N. J. Rv. E. Nucleus-independent chemical shifts: a simple and efficient aromaticity probe. J. Am. Chem. Soc. 118, 6317-6318 (1996).

38. Chen, Z., Wannere, C. S., Corminboeuf, C., Puchta, R. \& Schleyer, Pv. R. Nucleus-independent chemical shifts (NICS) as an aromaticity criterion. Chem. Rev. 105, 3842-3888 (2005).

39. Fallah-Bagher-Shaidaei, H., Wannere, C. S., Corminboeuf, C., Puchta, R. \& Schleyer, Pv. R. Which NICS aromaticity index for planar $\pi$ rings is best? Org. Lett. 8, 863-866 (2006).

40. Herges, R. \& Geuenich, D. Delocalization of electrons in molecules. J. Phys. Chem. A 105, 3214-3220 (2001).

41. Geuenich, D., Hess, K., Köhler, F. \& Herges, R. Anisotropy of the induced current density (ACID), a general method to quantify and visualize electronic delocalization. Chem. Rev. 105, 3758-3772 (2005).

42. Schleyer, Pv. R. \& Pühlhofer, F. Recommendations for the evaluation of aromatic stabilization energies. Org. Lett. 4, 2873-2876 (2002).

43. Wannere, C. S. et al. On the stability of large [4n]annulenes. Org. Lett. 5, 2983-2986 (2003).

44. Fernández, I., Frenking, G. \& Merino, G. Aromaticity of metallabenzenes and related compounds. Chem. Soc. Rev. 44, 6452-6463 (2015).

45. Kim, C., Favazza, C. \& Wang, L. V. In vivo photoacoustic tomography of chemicals: high-resolution functional and molecular optical imaging at new depths. Chem. Rev. 110, 2756-2782 (2010).

46. Wang, L. V. \& Hu, S. Photoacoustic tomography: In vivo imaging from organelles to organs. Science 335, 1458-1462 (2012).

47. Weber, J., Beard, P. C. \& Bohndiek, S. E. Contrast agents for molecular photoacoustic imaging. Nat. Methods 13, 639-650 (2016).

48. Kong, K. V. et al. Organometallic carbonyl clusters: a new class of contrast agents for photoacoustic cerebral vascular imaging. Chem. Commun. 50, 2601-2603 (2014).

49. Zhu, C. et al. Stabilizing two classical antiaromatic frameworks: demonstration of photoacoustic imaging and the photothermal effect in metalla-aromatics. Angew. Chem. Int. Ed. 54, 6181-6185 (2015).

50. Wang, J. \& Qiu, J. A review of organic nanomaterials in photothermal cancer therapy. Cancer Res. Front. 2, 67-84 (2016).

51. Qian, X. Q., Zheng, Y. Y. \& Chen, Y. Micro/nanoparticle-augmented sonodynamic therapy (SDT): breaking the depth shallow of photoactivation. Adv. Mater. 28, 8097-8129 (2016).

52. Huang, P. et al. Metalloporphyrin-encapsulated biodegradable nanosystems for highly efficient magnetic resonance imaging-guided sonodynamic cancer therapy. J. Am. Chem. Soc. 139, 1275-1284 (2017).

53. Rajora, M. A., Lou, J. W. H. \& Zheng, G. Advancing porphyrin's biomedical utility via supramolecular chemistry. Chem. Soc. Rev. 46, 6433-6469 (2017).

54. Lee, C., Yang, W. \& Parr, R. G. Development of the Colle-Salvetti correlationenergy formula into a functional of the electron density. Phys. Rev. B 37, 785-789 (1988).

55. Miehlich, B., Savin, A., Stoll, H. \& Preuss, H. Results obtained with the correlation energy density functionals of becke and Lee, Yang and Parr. Chem. Phys. Lett. 157, 200-206 (1989).

56. Becke, A. D. Density-functional thermochemistry. III. The role of exact change. J. Chem. Phys. 98, 5648-5652 (1993).

57. Hay, P. J. \& Wadt, W. R. Ab initio effective core potentials for molecular calculations. Potentials for $\mathrm{K}$ to $\mathrm{Au}$ including the outermost core orbitals. J. Chem. Phys. 82, 299-310 (1985).

58. Fukui, K. The path of chemical reactions-the IRC approach. Acc. Chem. Res. 14, 363-368 (1981).
59. Huzinaga, S. (ed.). Gaussian Basis Sets for Molecular Calculations (Elsevier, Amsterdam, 1984).

60. Frisch, M. J. et al. Gaussian 09, revision B.01. (Gaussian, Inc., Wallingford, 2009).

61. Wiberg, K. B. Application of the pople-santry-segal CNDO method to the cyclopropylcarbinyl and cyclobutyl cation and to bicyclobutane. Tetrahedron 24, 1083-1096 (1968)

62. Glendening, E. D. et al. NBO 6.0 (Theoretical Chemistry Institute, University of Wisconsin, Madison, 2013)

63. Dolomanov, O. V., Bourhis, L. J., Gildea, R. J., Howard, J. A. K. \& Puschmann, H. J. Appl. Crystallogr. 42, 339-341 (2009).

64. Sheldrick, G. M. SHELXT-integrated space-group and crystal-structure determination. Acta Crystallogr. A71, 3-8 (2015).

65. Sheldrick, G. M. Crystal structure refinement with SHELXL. Acta Crystallogr C71, 3-8 (2015).

\section{Acknowledgements}

This research was supported by the National Natural Science Foundation of China (Nos 21572185, 21561162001, and 81571744), the Research Grants Council of Hong Kong (N_HKUST603/15), the Excellent Youth Foundation of Fujian Scientific Committee (2018J06024), and the Fundamental Research Funds for the Central Universities (20720170065).

\section{Author contributions}

H.Z. conceived the project. X.Z., X.P., L.N., C.Z., K.Z. and G.L. performed the experiments. X.Z., C.Z. and Q.Z. recorded all NMR data. X.Z. and Z.C. solved all X-ray structures. X.Z., H.Z, Z.L. and H.X. analyzed the experimental data. X.P. and G.L. performed the SDT experiments. L.N. performed the PA experiments. K.Z. performed the photothermal experiments. H.Z conceived the theoretical work. H.Z., X.Z., Z.L. and H.X. analyzed and interpreted the computational data. H.Z., X.Z. and H.X. drafted the paper, with support from C.Z., Q.Z. and Z.L. All of the authors discussed the results and contributed to the preparation of the final manuscript.

\section{Additional information}

Supplementary Information accompanies this paper at https://doi.org/10.1038/s41467019-09367-8.

Competing interests: The authors declare no competing interests.

Reprints and permission information is available online at http://npg.nature.com/ reprintsandpermissions/

Journal peer review information: Nature Communications thanks Manabu Hoshino and the anonymous reviewers for their contribution to the peer review of this work.

Publisher's note: Springer Nature remains neutral with regard to jurisdictional claims in published maps and institutional affiliations.

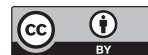

Open Access This article is licensed under a Creative Commons Attribution 4.0 International License, which permits use, sharing, adaptation, distribution and reproduction in any medium or format, as long as you give appropriate credit to the original author(s) and the source, provide a link to the Creative Commons license, and indicate if changes were made. The images or other third party material in this article are included in the article's Creative Commons license, unless indicated otherwise in a credit line to the material. If material is not included in the article's Creative Commons license and your intended use is not permitted by statutory regulation or exceeds the permitted use, you will need to obtain permission directly from the copyright holder. To view a copy of this license, visit http://creativecommons.org/ licenses/by/4.0/.

(C) The Author(s) 2019 